Michel-Kerjan, E. et al. (2011), "Catastrophe Financing for Governments: Learning from the 2009-2012 MultiCat Program in Mexico", OECD Working Papers on Finance, Insurance and Private Pensions, No. 9, OECD Publishing. doi: $10.1787 / 5 k g c j f 7 w k v h b-e n$

OECD Working Papers on Finance, Insurance and Private Pensions No. 9

\title{
Catastrophe Financing for Governments
}

LEARNING FROM THE 2009-2012 MULTICAT PROGRAM IN MEXICO

Erwann Michel-Kerjan, Ivan Zelenko, Victor Cardenas and Daniel Turgel 



\title{
Catastrophe Financing for Governments: Learning from the 2009-2012 MultiCat Program in Mexico
}

\author{
Erwann Michel-Kerjan ${ }^{1}$, Ivan Zelenko $^{2}$, Victor Cárdenas $^{3}$, and Daniel Turgel ${ }^{4}$
}

\begin{abstract}
With rapidly increasing population and growing catastrophe exposure in their countries, many more government leaders (including Presidents, Prime Ministers and heads of Kingdoms) are now faced with this strategic question: how best develop a national strategy to hedge against the massive economic burden of extreme events that could hit their country tomorrow?
\end{abstract}

We propose a framework to help those leaders in governments around the world and their advisors think more clearly about these issues, focusing specifically on the role that risk transfer mechanisms alternative to traditional insurance can play. The report provides a case study of the \$290 million multi-peril, multi-tranche catastrophe bond recently sponsored by the Government of Mexico and arranged by the World Bank under the MultiCat Program. We discuss the step-bystep creation of this catastrophe bond, from starting discussions that took place in 2008 to the investor road show and the successful issuance of the bond in October 2009.

This joint initiative could provide an example for other countries that wish to establish their own financial coverage solution against disasters, as part of a broader national risk management strategy. We illustrate this with the case of the government of Chile and earthquake risks. It also shows that considering countries, or even cities, for the issuance of such insurancelinked securities (ILS) could considerably expand this market for alternative catastrophe risk transfer instruments.

Key words: Catastrophe Economics; Risk Financing; Leadership in Government; Mexico; ART; MultiCat Program; Sovereign Catastrophe Bonds

\footnotetext{
${ }^{1}$ Address for correspondence: Wharton Risk Management and Decision Processes Center, OPIM Dept., The Wharton School, University of Pennsylvania, Huntsman Hall, Room 556, 3730 Walnut Street, Philadelphia, PA, 19104, USA.

Email: erwannmk@wharton.upenn.edu

${ }^{2}$ Email: izelenko@worldbank.org

${ }^{3}$ Email: cardenas.victor@gmail.com

${ }^{4}$ Email: dturgel@archrefac.com
} 



\begin{abstract}
About the Authors
Erwann Michel-Kerjan is Managing Director of the Wharton School's Risk Management and Decision Processes Center, a center with nearly three decades of experience in developing strategies and policies for dealing with catastrophic risks. He also teaches Value Creation in the Wharton MBA program. He is Chairman of the OECD Secretary-General Board on Financial Management of Catastrophes, which advises its thirty-four member countries on these issues. Dr. Michel-Kerjan was named a Young Global Leader (YGL) by the World Economic Forum (Davos), an honor bestowed to recognize and acknowledge the most extraordinary leaders of the world under the age of 40. He currently co-leads the Global Risks component of the G20 YGL Paris Initiative under the High Patronage of President Sarkozy. Dr. MichelKerjan is the author of several acclaimed books, including, most recently, At War with the Weather (MIT Press, with H. Kunreuther) and The Irrational Economist (PublicAffairs, with P. Slovic). He is a regular contributor in the media and has given over 100 public speeches. He has studied at Polytechnique in France, McGill and Harvard.
\end{abstract}

Ivan Zelenko is Head of Derivatives and Structured Finance at the World Bank Treasury, a position he has held since 2000. In parallel with leading the activities of the Bank in derivatives markets, he delivers advisory services to governments in areas that include catastrophe insurance or commodity price risk and carbon finance. Prior to this current position, Dr. Zelenko has held various positions in capital markets, finance or strategy departments at the French financial institution Caisse des Dépôts and also at the banks Crédit Agricole and Banque Nationale de Paris. He holds a $\mathrm{PhD}$ in Economics from the University of Paris Sorbonne. He graduated from the French leading schools Ponts et Chaussées and Sciences-Po. He has published several books and articles on finance and financial markets.

Victor Cárdenas is a consultant specializing in climate change and catastrophe risk management. He spent over nine years in different risk management positions within governments in developing economies and for multilateral financial organizations. He has participated in the development of risk management schemes for natural catastrophes in Latin America and Africa, as well as designed schemes for developing economies to handle the possible impact of climate change. His expertise focuses on financial risk management strategies combining structured insurance products and capital markets instruments such as options, swaps and insurance linked securities (ILS). Mr. Cárdenas was in charge, for the Ministry of Interior of Mexico, of guiding the establishment of the MultiCat program in 2009 and the first cat bond sponsored by the government of Mexico in 2006. He holds a Master's degree in Finance from the IE Business School in Spain and a BA in Economics from ITAM of Mexico.

Daniel B. Turgel is currently an underwriting director for Arch Re Facultative in Boston, Massachusetts covering all property risks. Prior to joining Arch Re Facultative, Mr. Turgel worked in Shanghai from 2004 - 2007 and then graduated from the MBA program of the Wharton School and from The Lauder Institute where his thesis concentrated on the under-developed debt markets in China and their effect on capital management for Chinese insurers. Mr. Turgel also holds a BA in Chinese and Russian Studies from the Ohio State University. 


\section{Acknowledgements}

The authors would like to thank Paolo Bazzurro, Laura Boudreau, Ignacio Briones, Amy Chang, Nikhil da Victoria Lobo, Claire Friedman, Jay Green, Rubem Hofliger, Beat Holliger, Shiv Kumar, Howard Kunreuther, Manuel Lobato, Vincent Meyers, Stuart Miller, Alberto Monti, Robert Muir-Wood, Andreas Müller, Richard Pennay, Salvador Perez, Marcus Schmutz, Reto Schnarwiler, Cecile Vignial, Pete Vloedman, and other team members at AIR Worldwide, Goldman Sachs, the Ministry of Finance and the Ministry of Interior of Mexico, the Ministry of Finance of Chile, and Swiss Re for their insightful comments on earlier versions of this report and discussions on the topic. Carol Heller, Greg Chianetta and Mike Chen provided excellent research assistance.

Partial financial support by the OECD, the World Bank and the Wharton Risk Management and Decision Processes Center is acknowledged. The authors' views expressed in this report do not necessarily reflect the views of these institutions. Usual disclaimers apply. 


\section{Table of Contents}

Introduction

1

PART A. DISASTER FINANCING AND ALTERNATIVE RISK TRANSFER …...............5

Section A-1. Catastrophe Risk Financing along the Economic Development Curve ..............7

Section A-2. Alternative Risk Transfer Instruments: A Useful Tool for Governments? ...........10

PART B. APPLICATION: THE MULTICAT PROGRAM IN MEXICO _..........................19

Section B-1. Government Responsibilities for Catastrophes in Mexico ..........................21

Section B-2. Preparation and Execution of the 2009-2012 MultiCat Program:

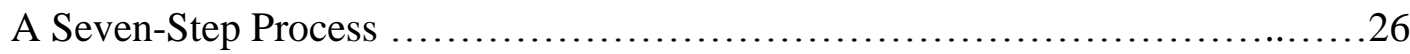

PART C. LESSONS LEARNED FOR CHILE AND OTHER COUNTRIES ......................37

Section C-1. Brief History of Chilean Earthquakes …....................................39

Section C-2. Economic and Insured Impacts of the 2010 Maulé Earthquake ...................41

Section C-3. Why the Selection of Disaster Financing Solutions Is Important .................42

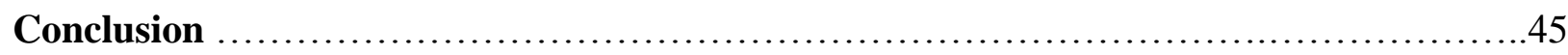

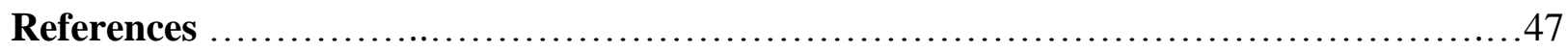

Appendices

Appendix 1: Cat Bond Series to Protect the U.S. California Earthquake Authority ..............49

Appendix 2: Cat Bond to Protect the Taiwanese Residential Earthquake Insurance Pool ........50

Appendix 3: Recent Catastrophe Bond Deals (January 2009-December 2010) ..................51 


\section{FIGURES and TABLES}

Figure 1. Cost of Natural Catastrophes Worldwide 1980-2010

Figure 2. A Simplified View on Governments' Responses to Financial Management of

Natural Disasters as a Function of their Economic Development with Respect to Risk,

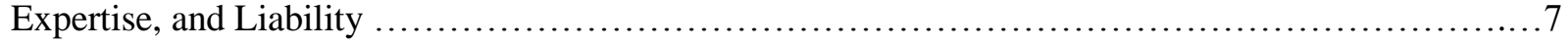

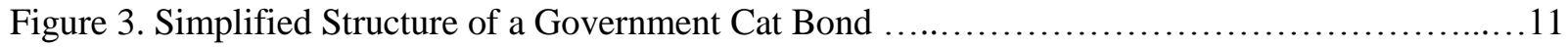

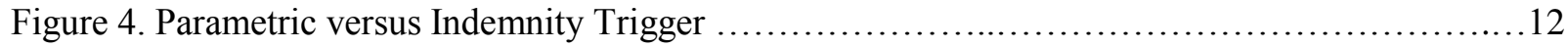

Figure 5. Cumulative Performance of the Swiss Re Cat Bond Index. January 2002-January 2011 .......15

Figure 6. Evolution of the Catastrophe Bond Market. January 1, 1997-December 31, 2010 ...........18

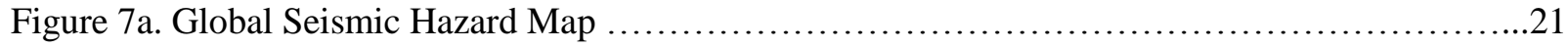

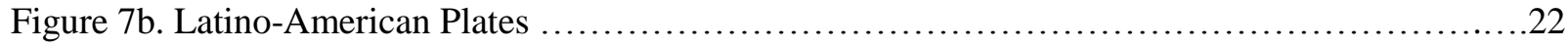

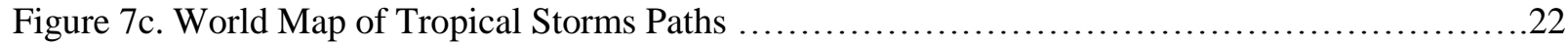

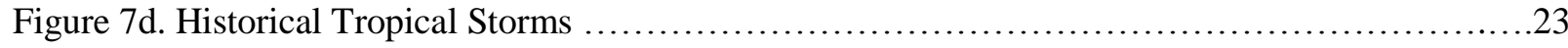

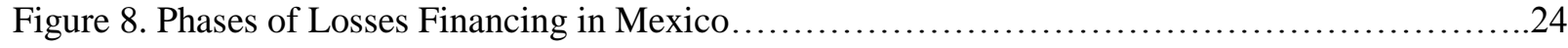

Figure 9. Mexico’s Fonden Budgeted and Spent Funds - 1999-2010 (in 2010 \$U.S.) .................25

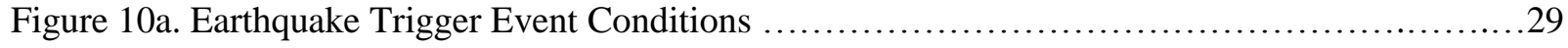

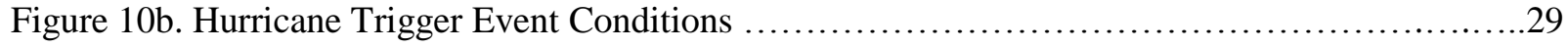

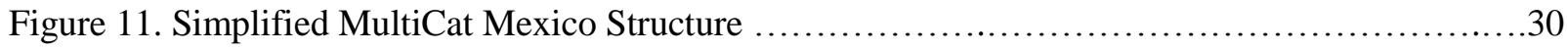

Figure 12. Triggering Events. Illustration with Trajectories of Some Pre-2009 Hurricanes

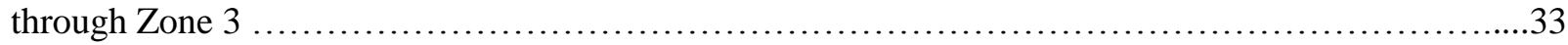

Figure 13. Estimated Annual Exceedance Probabilities of Select Historical Earthquakes in Chile ......43

Table 1. Mexico MultiCat Bond - Note Classes Description ..................................

Table 2a. MultiCat Mexico 2009-I Notes - Investor Distribution by Investor Type ...................34

Table 2b. MultiCat Mexico 2009-I Notes - Investor Distribution by Region ........................35

Table 3. Ten Costliest Natural Disasters in Chile, 1950-2010 (nominal) .......................40 


\section{Introduction}

\section{A New Era of Catastrophes}

Conventional wisdom holds that major accidents and disasters are low-probability events. In today's world, this view is clearly outdated. Catastrophes have unfolded at an unprecedented rate in the past few years: financial crises, large-scale natural disasters, intercontinental pandemics, and mega-terrorism. Consider also food and water scarcity, high climate variability, nuclear proliferation, and cyber-attacks. It seems that we have, indeed, entered a new era of catastrophes (Kunreuther and Michel-Kerjan, 2009).

On the natural disaster front, on which this report focuses, several socioeconomic factors have a direct influence on the escalating levels of economic losses resulting from catastrophic events: rapidly increasing population, higher degree of urbanization, and huge growth in value at risk. In 1950, approximately 30 percent of the world's population lived in cities. In 2000, about 50 percent of the world's population ( 6 billion) resided in urban areas. Projections by the United Nations show that by 2025, that figure will have increased to 60 percent based on a world population estimate of 8.3 billion people. Many of these growing cities are located in catastrophe-exposed areas which makes them extremely vulnerable to future disasters. Rapid real estate development that accompanied the growth in urban population often occurred without careful consideration for environmental protection (for example, the Louisiana wetlands which acts as a buffer against hurricane storm surge is considerably reduced today compared to its size 50 years ago).

The level of assets at risk has also significantly increased. Many countries have benefited from unprecedented economic development over the past decades. As a result of this massive economic growth, much greater assets are now at risk. In other words, the same earthquake, flood or hurricane will have a much more devastating human and economic impact today than if it had occurred 50 years ago when population and exposed assets were much lower (World Bank, 2010).

\section{A Financial Management View}

In OECD countries, which rely heavily on traditional insurance to access financial coverage against catastrophes, this evolution translates into a troubling figure: of the 25 most costly insured catastrophes that occurred over the period 1970-2010, more than half occurred since 2001. 2009 was a year of relatively few catastrophes, but still cost $\$ 26$ billion in insurance losses (Swiss Re, 2010a). As depicted in Figure 1, 2010 ranked $5^{\text {th }}$ among the most costly natural catastrophe years since 1980, with $\$ 150$ billion of economic losses. The 2010 Chilean and New Zealand's earthquakes cost respectively about $\$ 8$ billion and $\$ 4.4$ billion to insurers and reinsurers. The 2011 Tohoku, Japan earthquake and tsunami will likely inflict insured losses in the \$21 to \$34 billion range (RMS, 2011). 
Figure 1. Cost of Natural Catastrophes Worldwide 1980-2010

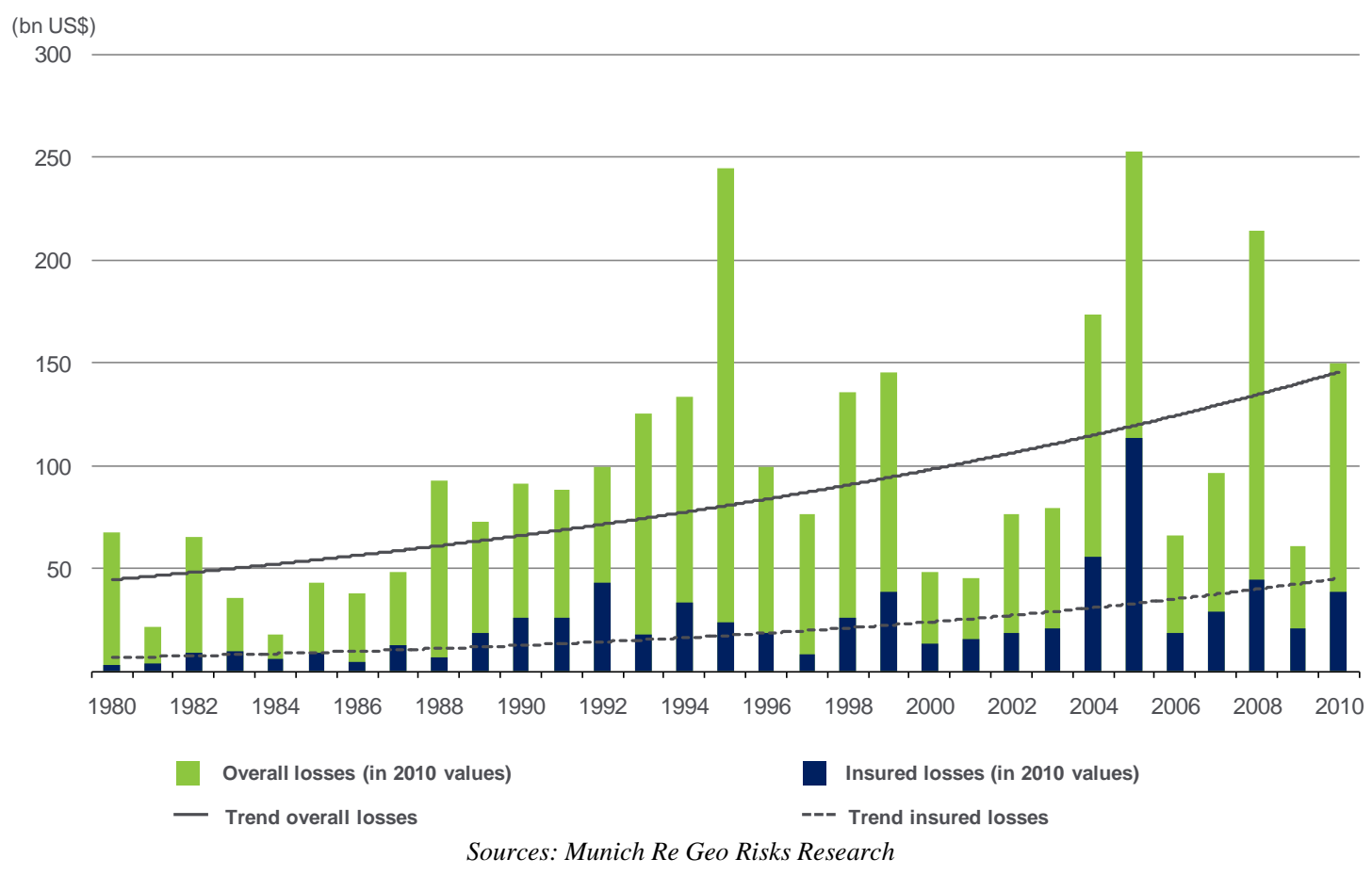

The insurance indicator is of course less relevant in many low- and middle-income countries where insurance is limited, if not absent. However, disasters are known to have more enduring negative effects on less-developed countries, oftentimes true poverty traps (Gurenko, 2004; Linnerooth-Bayer et al., 2005).

A recent study illustrates this aspect quite well, by comparing the economic impact of recent catastrophes on national economies (as measured as a percentage of their gross domestic product, GDP). It showed that while Hurricane Katrina, which hit the United States in 2005, cost nearly $\$ 150$ billion, that amount represented only 1.2 percent of the U.S. GDP that year. Similarly, the major 1995 Kobe earthquake in Japan cost nearly \$100 billion, which represented at that time about 3 percent of the country's GDP. At the other end of the spectrum, Hurricane Ivan in 2004 inflicted $\$ 900$ million in direct economic losses to the island of Grenada, which represented 200 percent of its GDP. Also in the Caribbean region, when Hurricane Gilbert hit the island of St. Lucia in 1988, it caused \$1 billion in losses - equivalent to 365 percent of its GDP (Cummins and Mahul, 2008).

The major earthquake in Haiti in January 2010 caused 300,000 direct and indirect deaths (due to lack of proper medical treatment post-disaster), and the historical flooding in Pakistan which affected over 20 million people and required massive donations from the international community to start the reconstruction process, are only recent illustrations of the devastating impact natural catastrophes can have in countries where government is not well prepared for them. 


\section{Focus and Outline of the Report: Protecting Public Finance}

In that context, this report raises the following question: What can you do, as a top government official, to make your country better prepared economically to face future catastrophes and to ensure fast economic recovery post-disaster? In an attempt to help answer this question, the report analyzes some financial solutions government officials might want to consider $e x$ ante when thinking about post-disaster economic resiliency. ${ }^{5}$

This is important because in many countries, low- or high-income alike, the government is the de facto insurer of last resort (people and firms will turn to their government for help if they don't have the resources to recover from the disaster). So this is also a matter of establishing more efficient public finance management in countries exposed to natural catastrophes (Moss, 2002; OECD, 2008; World Bank, 2010). Designing and implementing ex ante, need-oriented financial protection solutions would make the country less dependent on international donors, too, which will be seen as a signal of leadership toward sustainable economic development by the international community and at home. Even for high-income countries, with rising deficits and constrained fiscal spending in a post-financial crisis world, the economic and political value of the establishment of ex-ante financial protection solutions are important.

The government of Mexico provides an innovative example. Mexico, through its 2009 catastrophe bond issuance, has successfully transferred to specialized investors in the financial markets $\$ 290$ million of its exposure to hurricane and earthquake risks. The catastrophe bond (hereafter, "cat bond") provides three-year coverage for Mexico. Because Mexico was among the first governments in the world to use catastrophe-related alternative transfer instruments (ART) (alternative to traditional insurance and reinsurance) to protect its public finance, it constitutes a natural example for us to analyze. ${ }^{6}$ The case of the Mexican cat bond is also informative because the Mexican government benefited from very positive media coverage and praise from catastrophe specialists. Surprisingly, however, there has not been a detailed description of how that financial solution came to be chosen by that government, how it was designed, the key stakeholders who made the transaction possible, nor of how a similar process could be applied elsewhere with benefits to the national government. ${ }^{7}$

\footnotetext{
${ }^{5}$ Physical risk reduction measures (e.g., retrofitting houses to make them more resistant to earthquake, or elevating buildings to make them less prone to flood) as well as effective land use policy (e.g., avoiding high concentration of population and assets in high-risk areas) should also be considered as part of a national strategy for catastrophe risk management, but we focus here on the economic hedging component of such a strategy.

${ }^{6}$ Note here that a few other ART solutions have been used to cover insurance pools in which governments have exposure, including Ianus sponsored by Munich Re in 2009, which included protection against earthquakes for the Turkish Catastrophe Insurance Pool, or Formosa Re which covers potential losses to the Taiwan Residential Earthquake Insurance Pool (TREIP) (see Appendix 2). In the U.S., Alabama has recently used ART for hurricane coverage, as part of reinsurance coverage by Swiss Re. Some of the exposure to earthquakes of the California Earthquake Authority have also benefited from ART capacity (see Appendix 1). It was also recently proposed that the U.S. National Flood Insurance Program consider such instruments to reduce its exposure to catastrophic floods (Michel-Kerjan, 2010d).

${ }^{7}$ Mexico's first cat bond (CatMex) was issued for only earthquake coverage in 2006 as part of a $\$ 450$ million reinsurance program (the cat bond was for \$160 million); see Cárdenas et al. (2007) and Hardle and Cabrera (2010).
} 
This report is organized into three parts. Part A focuses on Disaster Financing and Alternative Risk Transfer. Section A-1 provides a simplified framework for decision makers to better appreciate options available to them to establish financial protection against catastrophes in their country ${ }^{8}$ : government relief/debt, public insurance, private insurance and reinsurance markets, and securitization (as was the case in Mexico). Focusing specifically on insurance linked securities, Section A-2 discusses some pros and cons for governments considering such solutions.

Part B presents the case of the MultiCat Program in Mexico. Section B-1 discusses the government's responsibility and strategy for dealing with financial consequences of natural catastrophes in Mexico. In particular, we discuss the central role played by the Fonden (the dedicated government disaster fund) since its creation in 1996. Benefiting from unique access to the decision makers who took part in the building effort over a period of 15 months, Section B-2 discuss the entire process of the development of the MultiCat Program in detail: from early discussions on the needs of the Mexican government to protect against earthquakes and hurricane risks, the selection of the partners, the risk assessment phase, up to the successful issuance of that catastrophe bond to the financial markets in October 2009. All along, we try to provide a balanced view of decisions that were made by those in charge and the experts who worked with them.

Since the massive earthquake which struck Chile in 2010, the Chilean government is considering various options to optimize the financial management of disasters at national level. In response to Chile's request to the OECD High-Level Advisory Board on the Financial Management of Catastrophes to help revisit its national strategy in this respect, in Part C, Lessons Learned for Chile and Other Countries, we discuss some of the lessons from the MultiCat program, which could be of relevance for the government of Chile. Section C-1 provides an historical look at natural disasters in Chile, which reveals that the country has been hit many times by earthquakes, including some of the most powerful ones recorded. Section C-2 discusses the 2010 Maule earthquake that inflicted about $\$ 30$ billion losses, $\$ 8$ billion of which was insured. This makes this earthquake one of the most costly ones in the history of insurance and reinsurance worldwide. Section C-3 highlights the importance of selecting an adequate cat bond design based on probabilistic risk assessment, national public policy priorities and other factors. We then conclude on the applicability of this type of instruments to other governments.

\footnotetext{
${ }^{8}$ While we focus on natural disasters, there are similarities here with other types of risk - pandemics, terrorist attacks, technological accidents - which if they materialize could also have severe negative effect on public finances.
} 


\section{PART A \\ DISASTER FINANCING AND \\ ALTERNATIVE RISK TRANSFER (ART)}





\section{A-1. Catastrophe Risk Financing along the Economic Development Curve}

In this section, we provide a simplified view of different options from which a government would typically choose, depending on its priorities and level of economic development. Figure 2 depicts a four-level approach, from very low-income countries to OECDtype countries.

Figure 2. A Simplified View on Governments' Responses to Financial Management of Natural Disasters as a Function of their Economic Development with Respect to Risk, Expertise, and Liability

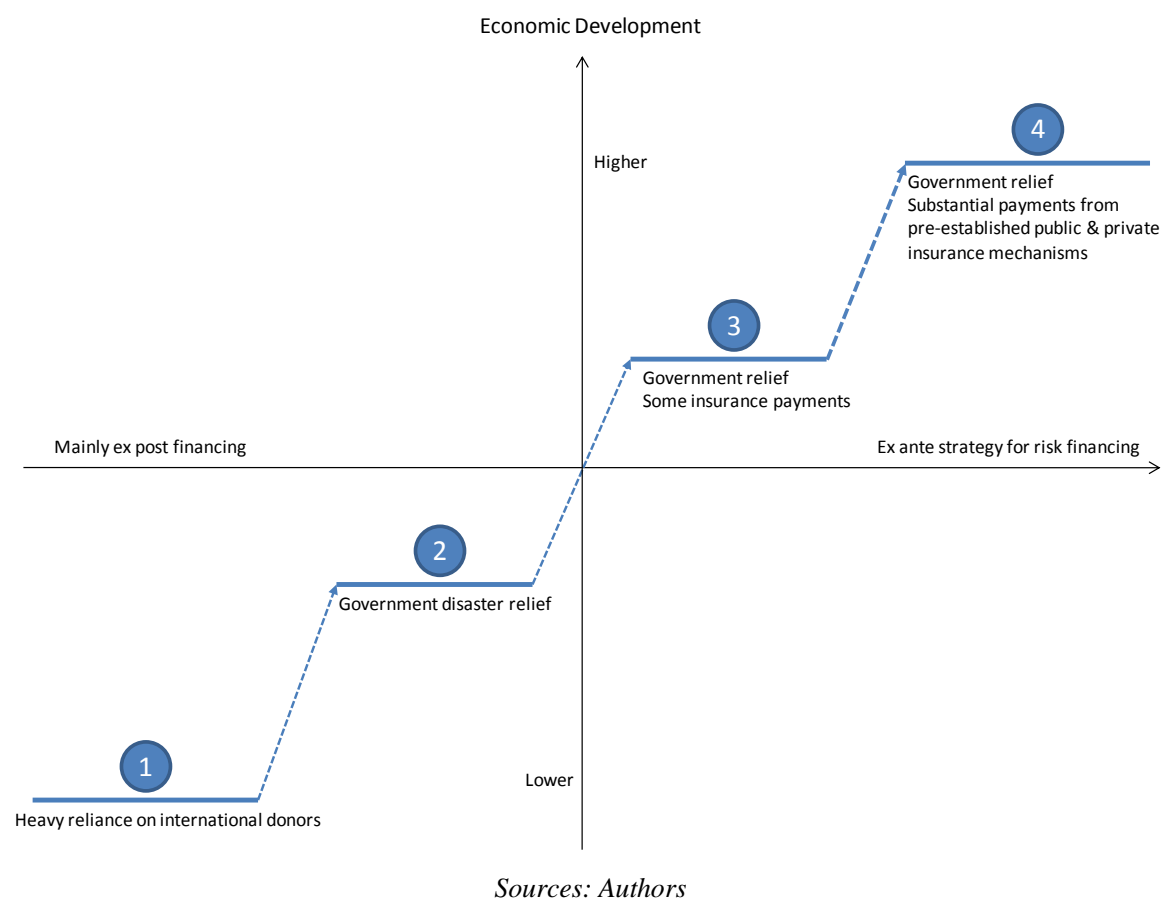

\section{Level 1: Very limited funding from central government; heavy reliance on donors}

In most low-income economies, a coherent national strategy for financial coverage against natural disasters is often absent. As a result, when a disaster strikes, the country relies essentially on ex-post funding from international donors such as the IMF, World Bank, European Commission, Inter-American Development Bank, UN Development Program, Asian Development Bank, and private charities. Victims often wait months before receiving financial help.

This level of government commitment requires the least dedication of resources prior to the event and therefore has the smallest upfront costs. But relying on other sovereign entities, or their policy institutions, can also create conflicts of interest between how and when the funds are deployed. Often, many of those low-income countries' governments are left with no other choice because they may not have in-house technical expertise to implement sustainable risk financing solutions in advance and on their own (Mechler, 2004; Ghesquiere and Mahul, 2010). They often favor short-term spending on critical issues their citizens face (access to food and drinkable water, health issues) over investment in longer-term strategies that will pay over time 
(e.g., investment in sustainable risk reduction measures). Furthermore, relying exclusively on international donors is a very uncertain strategy. For instance, the level of donations can be significantly lower if the disaster occurs right after a series of other large-scale disasters that have already triggered international media attention and might have created some donor fatigue (Michel-Kerjan, 2010c); the case of the historical flooding in Pakistan after the Haiti quake, the Chilean quake, the major flood in China, and Russian wildfires, all in 2010, is a good example.

\section{Level 2: Mainly ex-post funding from the central government}

As a country develops economically and the level of revenues the government can access through taxes increases, the government typically becomes the de facto relief provider for catastrophe risks. Post-disaster funding from the central government generates faster relief, improved effectiveness in coordinating disaster assistance, with better understanding of local customs (compared to complete reliance on international donors as described in Level 1). But the challenge here, too, is that funding is often inadequate without complementary international aid (Linnerooth-Bayer et al., 2005; Cummins and Mahul, 2008). Other impediments include improper spending of aid, improper type of aid provided, and of course political risk, since the central government decides who gets what first. The level of technical expertise in risk management in these countries is usually higher but still limited.

\section{Level 3: Some coverage by insurance systems; government is still the main funding source}

As the level of economic development improves, as described in Figure 2, we often see the establishment of dedicated catastrophe risk financing solutions. Public and private insurance and micro-insurance are present, although not providing coverage for a large portion of the population. At this level, private insurers begin to offer diverse products to provide property and casualty insurance alternatives for individuals, businesses, and public assets. Private insurance penetration is still low. The level of technical expertise in risk management within the national government is also often more developed than in Level 2. The disaster coverage solutions developed in these countries to protect the government often remain quite basic, though. The private markets in these countries have begun to provide some capacity but they have neither the capital base nor expertise to insure concentrated portfolios of risks.

\section{Level 4: Significant (re)insurance penetration; government supplements by allocating catastrophic risk capital}

In rich countries, insurance penetration and expertise is much more developed. People can often afford to pay for insurance coverage obtained through insurance markets or a national public insurance program. Still, even in the richest countries, the government typically continues to play an important role in providing some type of (re)insurance for truly catastrophic risks, or more generally, for risks the private sector does not want to cover alone. This is the case in the United States, Japan, Germany, France and the UK. ${ }^{9}$

\footnotetext{
${ }^{9}$ For instance, in the aftermath of Hurricane Katrina which hit the United States in August 2005, the private insurance and reinsurance industry paid $\$ 45$ billion in insurance claims. It remains the most costly event in the entire history of the insurance
} 
Looking at the OECD countries, one can observe that many of them have developed catastrophe financing solutions based on some type of public-private partnership, whereby the insurance industry provides insurance coverage for a given type of catastrophe and the government agrees to take steps to mitigate that risk across the country (e.g., flood insurance in the UK), and/or can also act as a reinsurer of last resort, effectively guaranteeing to pay out losses in excess of a predetermined catastrophic amount. ${ }^{10}$

But even in high-income countries, top government officials often struggle to find the right balance between economic efficiency (insurance cost must reflect the risk it covers plus the cost of capital required to provide this coverage) and equity issues (what to do to help those who cannot afford to pay for expensive catastrophe insurance). In Germany, for instance, flood insurance penetration is only ten percent for single-family homes (Thieken et al., 2006). After the major 2002 Elbe floods, the German government provided the largest amount of public funds to compensate uninsured flood victims ever paid in the country's history. These high-income countries are thus not immune to the charity hazard either: "Why buy insurance if the government is going to bail me out anyway?" (Browne and Hoyt, 2000; Raschky and Schwindt, 2008).

This is, of course, a simplified view of the catastrophe risk financing "world map." Some countries might be more advanced in dealing with specific risks they often experience while others may be less so. Some countries might have relied heavily on private insurance in the past, and are now letting more of the risk be transferred to the public sector, or vice versa. ${ }^{11}$ Importantly, there are three key variables in determining how a country moves along this curve: (1) the risk itself, (2) the level of expert knowledge about the risk available locally, and (3) the financial liability of the government (whether written or de facto).

Financial mechanisms that transfer catastrophe risk exposure of an organization or country directly to (re)insurance and/or international capital markets, typically in the form of a catastrophic reinsurance scheme, catastrophe bond or a catastrophe contingent loan cantheoretically at least - provide considerable value to countries at all four levels of development. For example, these mechanisms can help alleviate some of the political pressure that might occur if a government raised a public insurance fund through taxation (pressure which tends to intensify during periods of budget constraint). In practice, however, using ART as part of a national strategy for disaster management will probably require the government to retain international expertise and might not be adequate, depending on the country's needs and national priorities set by its leadership. Indeed, only a handful of governments have developed in-house technical knowledge on these ART solutions, which we now discuss in more detail.

industry worldwide. But most of these payments were for coverage against wind. The federally-run National Flood Insurance Program paid another $\$ 13$ billion for coverage against flood. The federal government provided another $\$ 89$ billion in relief. In total, even for the richest country in the world, the federal government paid twice what private insurers provided (Michel-Kerjan, 2010d).

${ }^{10}$ This is the case in nine of the thirty-four OECD countries for terrorism risks (Michel-Kerjan, 2010b; OECD, 2005).

${ }^{11}$ See Kunreuther and Michel-Kerjan (2009), OECD (2008), von Ungern-Sternberg (2004), Froot (1999), Kunreuther and Roth (1998) for more detailed analyses of the public-private catastrophe risk sharing in OECD countries, and Cummins and Mahul (2008) for low-income countries. 


\section{A-2. ALTERNATIVE RISK TRANSFER INSTRUMENTS: A USEFUL TOOL FOR GOVERNMENTS?}

The field of alternative risk transfer (ART) grew out of a series of insurance capacity crises in the 1970s through the 1990s that led purchasers of traditional reinsurance coverage to seek more robust ways to buy protection. Although ART instruments can comprise a wide range of alternative solutions (including the creation of captives or risk-retention groups), we concentrate here on instruments that transfer part of the risk exposure directly to investors in the financial markets. ${ }^{12}$ Most of these risk transfer techniques permit investors to play a more direct role in providing financial protection.

Here we focus on one insurance-linked instrument-catastrophe bonds-which has significantly grown in volume in recent years, and which is likely to continue to grow as a market as we witness more and more costly catastrophes in the coming years.

\section{How does it work?}

Catastrophe bonds ("cat bonds") can enable a country, a (re)insurance company or any other corporation or organization to access funds from investors if a severe disaster produces large-scale damage. To illustrate how cat bonds work, consider a country, ProactiveCountry, which would like to cover part of its exposure against catastrophes. To do so, it creates a company, BigCat, whose only purpose is to finance the disaster costs of ProactiveCountry. Notably, BigCat is not a government-run company but an independent company, typically located in Bermuda or the Cayman Islands where the tax treatment is more advantageous. In that sense, BigCat is a single purpose insurer (also called a special-purpose vehicle, or SPV) for ProactiveCountry. When the insurance contract is signed, the sponsor (ProactiveCountry) pays premiums to BigCat.

On the other side, SPV BigCat raises the capital to support its insurance policy by issuing a bond to investors. The investors' funds provided in exchange for the bond notes constitute the initial principal of the bond and will be placed in safe investments. In the case of a triggering event, as defined by the specifications of the issued bond, interest on the bond or the principal, or both, is forgiven, and these funds are then released to ProactiveCountry to help cover its claims from the event. This also means that ProactiveCountry can potentially face currency risk if the bond is dominated in a currency other than its own.

Premiums collected from ProactiveCountry will be used to provide the investors with a high enough interest rate to compensate for a possible loss of their principal should a disaster occur. One of the main advantages for investors (typically dedicated ILS funds, hedge funds, and money managers) is that these instruments constitute a different class of assets that can enhance

\footnotetext{
${ }^{12}$ See Anderson et al. (2000) and Cummins and Weiss (2009) for comprehensive journal articles, Lane (2002) and Barrieu and Albertini (2009) for edited volumes, and WEF (2008), Michel-Kerjan (2010a) and OECD (2010) for a more general analysis.
} 
their returns since they are not highly correlated with other financial risks (for example, fluctuations in interest rates, if the economy is in a recession or a boom).

Figure 3. Simplified Structure of a Government Cat Bond

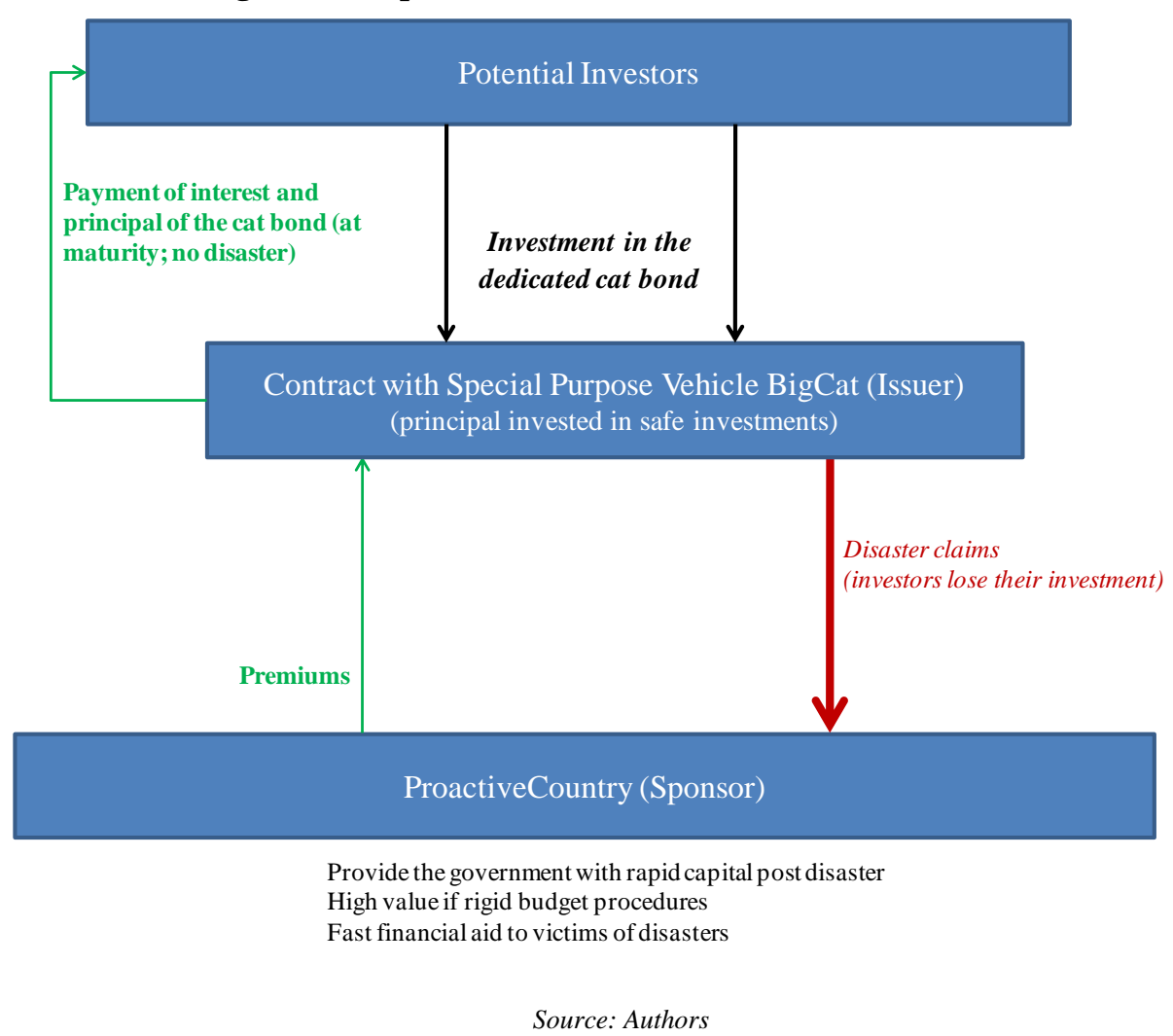

If we assume that a single natural disaster cannot seriously impact the world economy, the cat bond will earn a yield spread aligned with compensation for expected losses. The challenge for investors is thus that they can lose part or all of their capital and interest in the aftermath of a disaster covered by the cat bond. A high degree of regional portfolio diversification is therefore required for such investors, so that the loss of the entire capital/interest in one bond following a large hurricane like Katrina would represent only a few percentage points in terms of return on their portfolio. Of course, the need for diversification is dependent on who the investor is. Since many institutions have large investment portfolios but invest in ILS only through specialized funds, those funds themselves do not necessarily need to be diversified in their ILS holdings. However, when viewed at the level of a single institutional investor, that investor would want to have only a small part of their overall portfolio exposed to a particular cat risk. 


\section{When and how does ProactiveCountry receive money from the cat bond?}

There are several widely used ways the payment of a cat bond can be triggered. First, all the stakeholders can agree at the execution of the contract on an external trigger for the insurance payment, independent of the actual level of losses the country has suffered, but easily verifiable since it can be measured by technology in real time, and therefore allowing funding to come quickly. For instance, the agreed upon trigger could be "an earthquake of moment magnitude (Mw) 7.0 or more" in a specific city or region of the country, or "a major storm with highest sustained wind speed higher than $150 \mathrm{~km}$ per hour" in that same location. If one of these two events is measured during the period covered by the cat bond (called term of the bond), then the cat bond pays out. This is called a parametric trigger. Note that data for this parameter can also be collected at multiple reporting stations across a given geographical area and then entered into specified formulae, which define a particular index; one then talks of parametric index trigger.

It is also possible to agree on a certain level of the actual economic losses incurred by ProactiveCountry from a disaster or series of disasters over the maturity of the cat bond. This is an indemnity trigger. ${ }^{13}$ The main advantage of an indemnity trigger is that the payment received by ProactiveCountry will be much closer to its actual loss (thus reducing what is called the basis risk; i.e., the difference between the loss and what can be claimed: the absence of basis risk means that the payment covers 100 percent of the insured claims; Figure 4). The limitations, however, are that it might take much longer to compile that exact amount and there is a risk of its manipulation. Parametric cat bonds are thus often more transparent and simpler to use and have been the preferred trigger type in lesser developed countries.

Figure 4. Parametric versus Indemnity Trigger

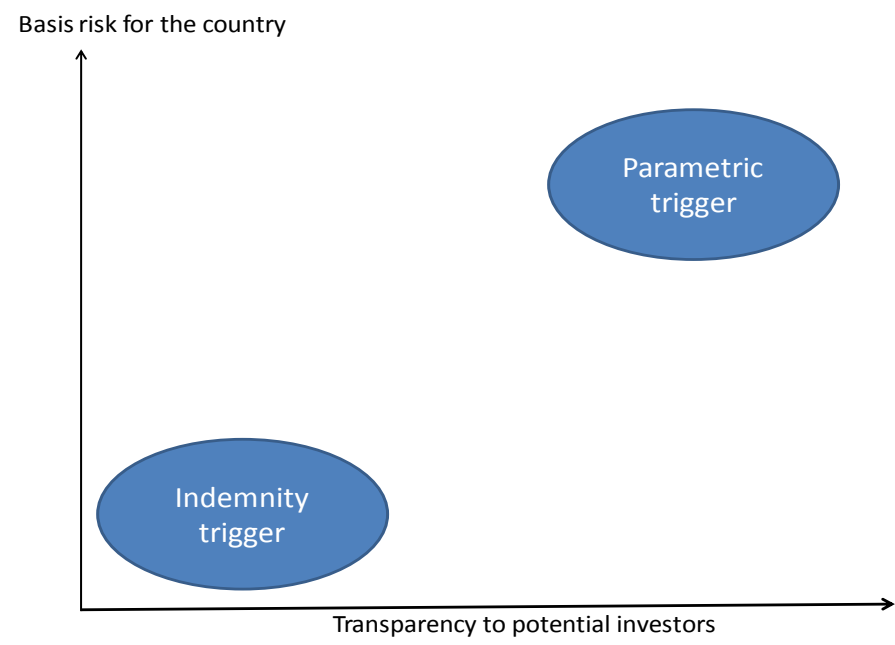

\footnotetext{
${ }^{13}$ This form of cat bond trigger is more analogous to a traditional insurance policy with its loss settlement process. Other triggers are on modeled losses or industry losses. For modeled losses, instead of dealing with ProactiveCountry's actual losses, an exposure portfolio is constructed for use with catastrophe modeling software; then when there is a disaster, the event parameters are run against the exposure database in the cat model. If the modeled losses are above a specified threshold, that triggers the bond. For industry losses, the cat bond is triggered when an entire industry loss from a certain peril for the insurance industry doing business in this country reaches a specified threshold.
} 


\section{Advantages for a government of using a cat bond}

(1) Multi-year coverage and price stability. Insurance and reinsurance contracts are typically issued for one year and thus subject to price jumps in premiums in international markets - jumps which can be particularly wide after a large-scale disaster. In the context of highly volatile reinsurance prices that often occur after large catastrophes, ${ }^{14}$ cat bonds offer an important element of stability for their users by guaranteeing a predefined price over several years, assuming that the entire capital of the bond is not triggered. More than 170 cat bonds have been issued since 1996 and their average maturity was 3 years, but nothing precludes those bonds from being longer as has been the case for a few of them. Longer bonds reduce upfront costs by allowing fees to be amortized over a longer period of time. We believe that this stability advantage has been largely undervalued so far (Michel-Kerjan and Morlaye, 2008).

(2) Guaranteed expedited payment. Another key advantage for a country to issue a cat bond is that the money is ready to flow to the government in just a few weeks, depending on the form of trigger. By design, the capital of the bond is commonly invested in risk-free assets, such as U.S. Treasury money market funds. As a result, there is limited credit risk (i.e., the very real possibility that an insurer or reinsurer that covers against a disaster goes bankrupt and cannot honor its obligation to pay the insured). In other words, because the proceeds of the cat bond are fully collateralized, the coverage obtained will last over the entire life of the transaction, subject to no triggering events causing a reduction of principal. ${ }^{15}$

(3) Potentially easier to manage politically than a government reserve. As discussed above, a natural financial policy tool for governments is to build up a reserve of money over time to be used in the case of a catastrophe. The way this is typically done is through insurance premiums and/or a portion of tax revenues specifically allocated to a catastrophe fund.

While the concept is simple to understand, in practice the catastrophe fund option is not always easy to implement and maintain over the long term. First, it might take years to build this reserve. A catastrophe could occur in the very first years such that the fund simply does not have enough money to pay for the losses. Second, if the country does not suffer major losses for a long period, attention fades. We know from experience in many countries that large reserves in a government program that were built over time are subject to reallocation. In this instance, the catastrophe reserve fund may be criticized for charging too much. ${ }^{16}$ Also, in difficult economic times, where government budgets are tight and public deficits grow, a large amount of money "sitting" will be viewed as a luxury many countries feel they can simply not afford. This is the

\footnotetext{
${ }^{14}$ The Guy Carpenter Rate-on-Line index shows a 30 percent annual volatility over the past ten years. Premiums also differ markedly among perils that increase the concentration of risk to the reinsurers and perils which provide diversification. And it is not unusual to see reinsurance prices in a region increase by 20 to 50 percent after a major disaster. Catastrophe reinsurance prices in Florida increased by nearly 100 percent the year after Hurricane Katrina (Kunreuther and Michel-Kerjan, 2009, chapter 7).

${ }^{15}$ Note that some reinsurers now provide collateralized reinsurance treaties as well, but those are more expensive than traditional reinsurance treaties.

${ }^{16}$ This was suggested in the United States for the Hurricane Relief Fund in Hawaii in 2009. Another example relates to the U.S. Pension Benefit Guaranty Corporation. In the 1990s there were interest groups lobbying the PBGC to reduce premiums because they were "too high," as evidenced by the fact that the PBGC was running a surplus.
} 
economic challenge of finding a balanced approach to the financial management of catastrophes. Because they do not happen frequently, it is imperative to keep a long-term view. But this is very hard to do because we are all short-term minded and do not know when those "possible" catastrophes will happen, if at all (Michel-Kerjan and Slovic, 2010). Similar to insurance and reinsurance, cat bonds overcome these challenges, since the catastrophe portion of the risk is transferred to third parties at the execution of the contract in return for a premium.

\section{Advantages for catastrophe bond investors}

One of the main advantages of investment in catastrophe bonds is that these instruments are typically not correlated with other traditional financial products and have had a good financial performance before and during the financial crisis. ${ }^{17}$ In 2007 , Swiss Re began compiling cat bond investment performance indices that are based on secondary market trading, extending the indices back to 2002. These indices allow us to compare the performance of this cat bond market to other market performance. Figure 5 below represents the relative performance of the Swiss Re Cat Bond index compared to the U.S. S\&P 500 index.

Over the past few years, the investor base has not only surged in volume but has also changed its structure. Once viewed as an alternative source of financial protection for reinsurance and insurance companies familiar with the risks and eager to diversify their exposure, ILS have now become another family of investment products for alternative investors such as hedge funds, dedicated ILS funds, and also money managers, pension funds or insurance companies. These investors are sophisticated, and are drawn by the features of the ILS (high Sharpe ratio and low correlation with traditional capital market assets). ${ }^{18}$ Mutual funds and money managers are also becoming more active in the market, eager to benefit from the highyielding instruments in the context of flat interest rates and historically low yields on government and corporate bonds.

\footnotetext{
${ }^{17}$ This might not be the case for truly devastating disasters, though, which could have significant and enduring ripple effects on financial markets. Cummins and Weiss (2009) provide an insightful empirical analysis of the correlation of cat bonds with other financial assets before and during the 2008 financial crisis. "Cat bond total returns have almost no correlation with returns on alternative investments during the mostly normal market conditions represented by January 2002 through June 2007. Cat bond coupon returns are highly correlated with the LIBOR and US government bond yields, but this is expected because cat bonds are priced at spreads over LIBOR and SPV trust assets often consist of government bonds. Therefore, during normal conditions, cat bonds are close to zero-beta with respect to stock and bond total returns.” For the period July 2007 through early January 2009 , their analysis shows a difference, though. "Cat bond total returns during the crisis are significantly correlated with three of the total return indices - the Merrill-Lynch BBB corporate bond index, the Barclays CMBS index, and the S\&P 500 stock index, with correlations ranging from 0.19 (for CMBS) to 0.465 (for BBB corporates). However, even during the crisis, the bivariate correlations indicate the cat bonds would be valuable for diversification, for example, the correlations with stocks are still relatively low and cat bonds are not significantly correlated with the Barclays government bond index. Hence, cat bonds could still be used effectively to diversify portfolios containing most types of stocks and bonds. Nevertheless, they were not zero-beta during this crisis; that is, like most other assets, they can be somewhat susceptible to systemic risk."

18 Sharpe ratio: A relative measure of a portfolio's return-to-risk ratio (i.e., return above the risk-free rate divided by its standard deviation. It is often used to determine the amount of excess return required by investors for an additional unit of risk).
} 
Figure 5. Cumulative Performance of the Swiss Re Cat Bond Index. January 2002-January 2011

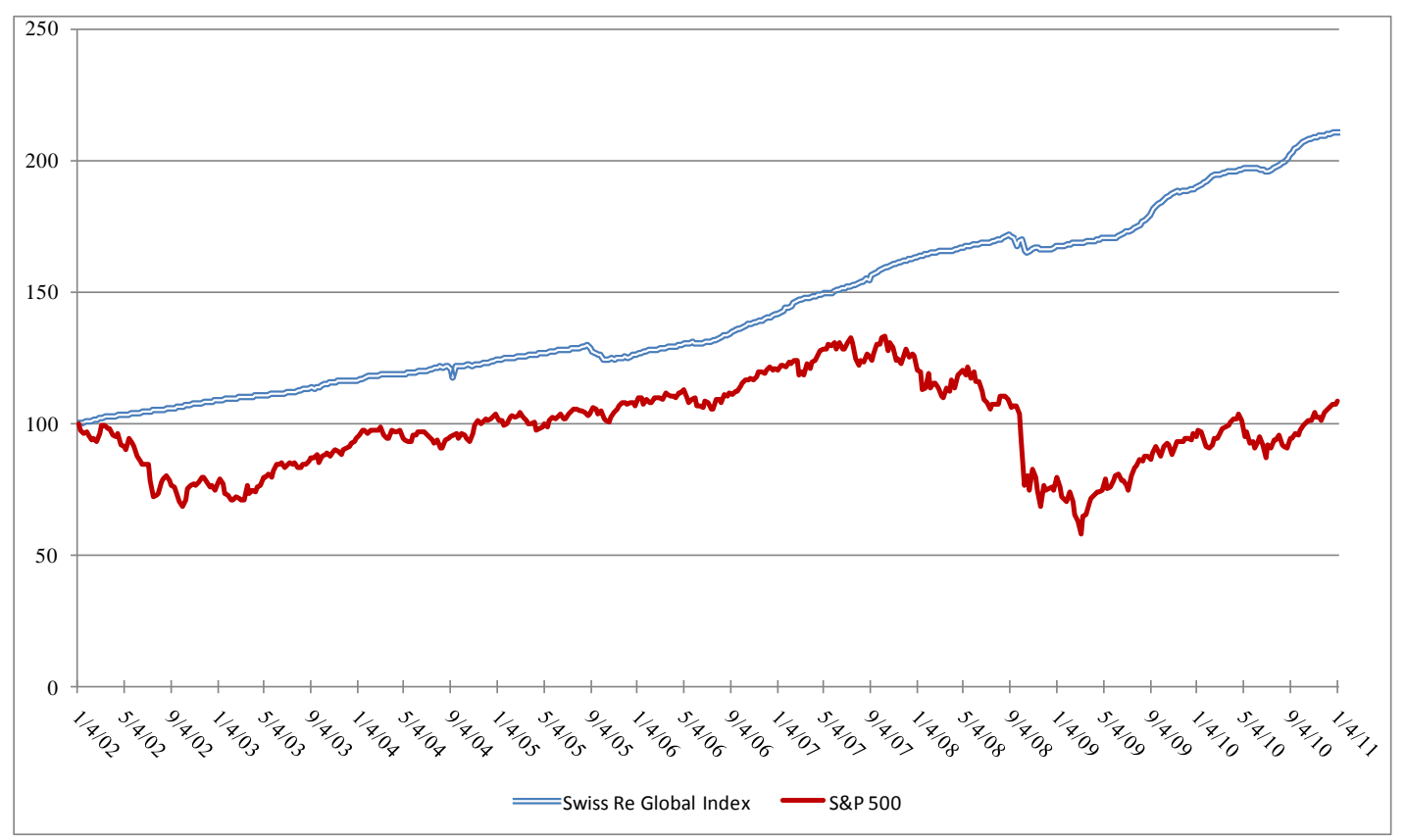

Sources: Authors, with data from Swiss Re

\section{Cost and pricing of cat bonds}

While cat bonds can present several advantages, they also come at a cost. How much is paid to investors in a cat bond? This is obviously the hardest question to answer in general. It depends very much on the expected losses that the cat bond covers, the maturity, the attachment point and limit (layer of the losses covered by the bond), the trigger, and when it is issued (notably because the cost of capital on the international markets varies constantly). Cat bonds are priced at spreads over a benchmark rate (i.e., the London Interbank Offered Rate (LIBOR) or U.S. Treasury money market funds), which means that investors in cat bonds will receive a spread over this floating interest rate.

Also, many transactions are made "over the counter" (that is, not publically monitored), which prevents the establishment of a straight price comparison, rendered even more difficult by the fact that most insurance treaties are tailored to the specific needs of the insured. Some information can be gathered by looking at the secondary market prices in cat bonds that make insurance premiums public. Information on secondary market prices is collected on a regular basis by banks, reinsurance companies and brokers active in the market (e.g., Guy Carpenter, Aon, Willis). Prices can be compared among cat bonds by expressing all insurance premiums as multiples of the expected loss. ${ }^{19}$ In 2001 , the ratio of premium to expected loss was relatively

\footnotetext{
${ }^{19}$ Because most cat bonds issued to date have been providing reinsurance for peak perils, capital market investors tend to face the same diversification issues as reinsurance companies after a number of years in the market. Cat bond pricing tends to be above reinsurance pricing for peak perils because the peak peril risk-taking capacity from the capital markets has not grown quickly enough to date and therefore there has not been downward pressure on prices that would result from an increased supply of capital.
} 
high at around 6, then declined steadily down to nearly 2 just before Hurricane Katrina in 2005. As a result of the 2005 hurricane season, it increased significantly again, then returned to lower levels (in the range of 2.5 to 3 during 2007 and 2008) (Lane and Mahul, 2008; Cummins and Weiss, 2009). How does this compare to more traditional reinsurance? Ratios of premiums to expected loss in the reinsurance markets have been shown to be in the 3 to 5 range (if not higher for the higher layers of coverage which corresponds to what cat bonds typically cover) (Froot and O'Connell, 2008; Cummins and Mahul, 2008).

A fundamental insight on asset pricing by Arrow (1964) and Debreu (1959) is that the value of an asset should be determined by both its distribution of payoff across economic states and state prices. As shown by Coval et al. (2009), "securities that fail to deliver their promised payments in the 'worst' economic states will have low values, because these are precisely the states where a dollar is most valuable. Consequently, securities resembling economic catastrophe bonds should offer a large risk premium to compensate for their systematic risk." In that sense, the current cat bond prices should be seen as quite attractive for developing countries whose economy can be seriously affected by a natural catastrophe (compared, for example, to raising capital the day after a disaster).

Developing cat bonds implies a number of transaction costs: risk assessment by a modeling firm, administrative costs for setting up the special purpose vehicle, legal costs, rating agency fees and the lead manager fee (i.e., underwriting fee). ${ }^{20}$ Underwriting fees can be in the range of 80 basis points ( 0.8 percent) to 200 basis points ( 2 percent) times the principal of the bond (paid once on issuance date), but will ultimately be negotiated based on the size and structure of the bond. For example, a fee of 100 basis points on a $\$ 200$ million cat bond would be $\$ 2$ million. These costs decrease for a regular issuer of cat bonds; that is, if ProactiveCountry in our above example issued several bonds over the years then the fees in subsequent issuances could be lower (in this case, one typically builds an "open shelf" dedicated to that issuer to reduce underwriting fees of future cat bonds). Costs are also reduced in relative terms as the maturity lengthens (since the upfront cost is spread over more years).

More relevant is the general fee structure - which varies with specific trades and depends on their difficulty - which we describe below and for which we give approximate numbers (all these fees would be paid one time, either before launch or in the first year of the cat bond). All are in basis points of the principal of the bond (100 bps $=1$ percent $)$ :

\footnotetext{
${ }^{20}$ What is typical of reinsurance markets is the use of a broker (Willis, Benfield, Guy Carpenter, etc.) to stand between the buyer of insurance and the reinsurance companies placing a bid. The reinsurance broker gets 5 percent to 10 percent of the insurance premium every year. The total broker costs may be even higher (an additional 5 percent to 10 percent of the premium) if additional intermediaries such as a retail broker are also involved. In emerging markets which may also require a local fronting company, these intermediation costs may run to as much 25 percent to 30 percent of the overall premium costs on traditional insurance placements for government entities. There also will be legal costs associated with setting up the reinsurance treaty.
} 
- Lead Manager / Arranger / Adviser fees: in the 80 bps to 200 bps range; paid at launch; ${ }^{21}$

- Legal fees: about 50 bps (or $\$ 500,000$ for a $\$ 100$ million bond);

- $\quad$ Risk modeling fees: about 10 to 50 bps, but depends on the size and trigger of the bond;

- SPV Administrator fee, expenses associated with administration: 3 to 4 bps (or more depending of the size of the bond);

- $\quad$ Rating agencies fees: around 6 to 7 bps.

\section{How many cat bonds have been issued, and for what financial capacity?}

Cat bonds have been on the market since 1994. More than 170 cat bonds were issued between 1997 and December 31, 2010, with a strong growth trend in recent years. As an indication, the risk capital issued during 2005 and 2006 was equal to the total capital issued over the preceding five years. Bonds outstanding increased significantly, too, which reflects the issuance of multi-year bonds in previous years. This trend continued in 2007, with 27 new catastrophe bonds issued for a total of $\$ 7$ billion in capital and raising the total capital outstanding to $\$ 14$ billion. As have other financial instruments, catastrophe bonds have suffered from the 2008-2009 financial crisis. After the 2007 record-setting year, catastrophe bond issuances fell 62 percent by volume ( $\$ 2.7$ billion in new and renewal capacity) and nearly by half in transaction amount (13), with almost no transactions taking place in the second two quarters of 2008. Indeed, given the uncertainty associated with the future of financial markets, the cost of capital, and more favorable reinsurance rates, many transactions were postponed.

Still, with $\$ 2.7$ billion of new issuances, 2008 was the third busiest year since catastrophe bonds were introduced in 1997. Cat bond issuance in 2010 rebounded significantly with 26 transactions totaling $\$ 5$ billion and $\$ 13$ billion outstanding capital (Swiss Re, 2010b and www.Artemis.bm). Figure 6 below depicts this evolution. In terms of level of coverage provided by these bonds, they are typically in the $\$ 100$ million to $\$ 300$ million range, with issuance historically as low as $\$ 50$ million and as high as $\$ 1.2$ billion (see Appendix 3 for the list of cat bond deals in 2009 and 2010). ${ }^{22}$

\footnotetext{
${ }^{21}$ The World Bank would typically ask 10 to $15 \mathrm{bps}$ of the nominal of the bond as an arranger, but this would depend on the nature and complexity of the transaction as well as ongoing work with the country.

${ }^{22}$ In 2007, the insurance giant State Farm issued a $\$ 1.2$ billion risk capital bond, the largest cat bond ever issued. The bond covers the company's portfolio in the case of cumulative losses resulting from a series of pre-defined events (hurricanes in the United States, earthquakes in Japan and others) over the three-year maturity of the bond (Kunreuther and Michel-Kerjan, 2009).
} 
Figure 6. Evolution of the Catastrophe Bond Market. January 1, 1997-December 31, 2010

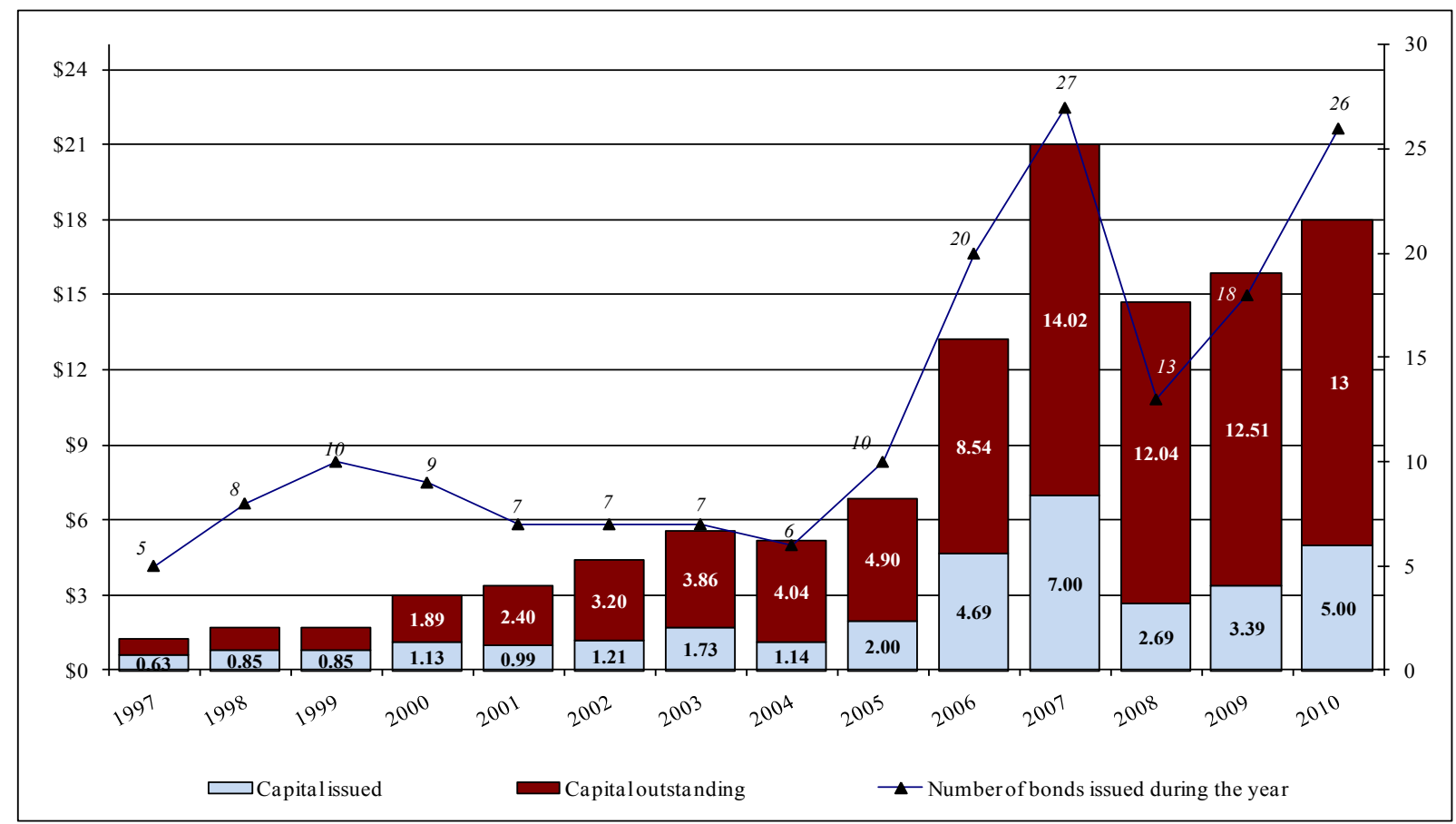

Sources: Data from Goldman Sachs and Swiss Re

\section{Technical knowledge required to use such bonds: how international expertise can help}

While alternative instruments like cat bonds can, in theory, provide many advantages to countries that look to establish some degree of financial protection against possible disasters, they can also be more difficult technically to understand and implement than the simple operation of insurance (collecting premiums, aggregating them nationally, and using them to pay claims). A country might not have the right financial experts working for their government to oversee all the steps of the issuance of a catastrophe bond. That might be one of the reasons why no government had directly used a catastrophe bond in the first decade of their existence (OECD, 2010). Until 2006, all cat bonds had been issued by corporations, most of which were sophisticated insurers and reinsurers looking for protection of their portfolio. And the corporate world remains the main source of cat bond issuances today (Spry, 2009).

Still, given the recent series of catastrophes that occurred in the world and serious challenges to the financial stability of several countries, governments could gain from the development of easier access to ART instruments. For this, they might first need to retain technical expertise in catastrophe financing instruments from experts in the field, and use this expertise to build up their own internal capacity over time. The case of Mexico working with the World Bank and private sector partners is illustrative and could constitute a valuable model for many low- and middle-income countries to consider. We now turn to a detailed discussion of this cat bond program. 


\section{PART B}

\section{APPLICATION: THE MULTICAT PROGRAM IN MEXICO}





\section{B-1. GOVERNMENT RESPONSIBILITIES FOR CATASTROPHES IN MEXICO}

\section{Mexico's Exposure to Catastrophe Risks}

Mexico's territory covers a large and diverse geographical area and is highly exposed to a wide range of natural hazards such as earthquakes, droughts, hurricanes, mudslides and volcanic activity. For instance, Mexico City and its metropolitan area, one of the world's largest cities with 20 million people, is particularly vulnerable to earthquakes (see Figures $7 \mathrm{a}$ and $7 \mathrm{~b}$ below). In 1985, a major magnitude 8.1 earthquake hit the city, killing 9,500 people and injuring 30,000 others; nearly 100,000 houses were damaged or totally destroyed (Swiss Re, 2010a). Estimates put the direct economic cost of this disaster at $\$ 7.9$ billion in 2010 prices (or $\$ 4$ billion at that time). Mexico is also prone to hurricanes; many have hit the country in the past decades (Figures $7 \mathrm{c}$ and $7 \mathrm{~d}$ ). When Hurricane Wilma severely affected the Yucatan Peninsula in October 2005, it badly damaged the tourist region, resulting in losses of more than $\$ 1$ billion. As rapid urbanization has led to hyper-concentration of risk in many areas, vulnerability is increasing, especially for the poor, as they often live in the areas with the highest risk and do not have the financial resources to invest in risk reduction measures. ${ }^{23}$

Figure 7a. Global Seismic Hazard Map

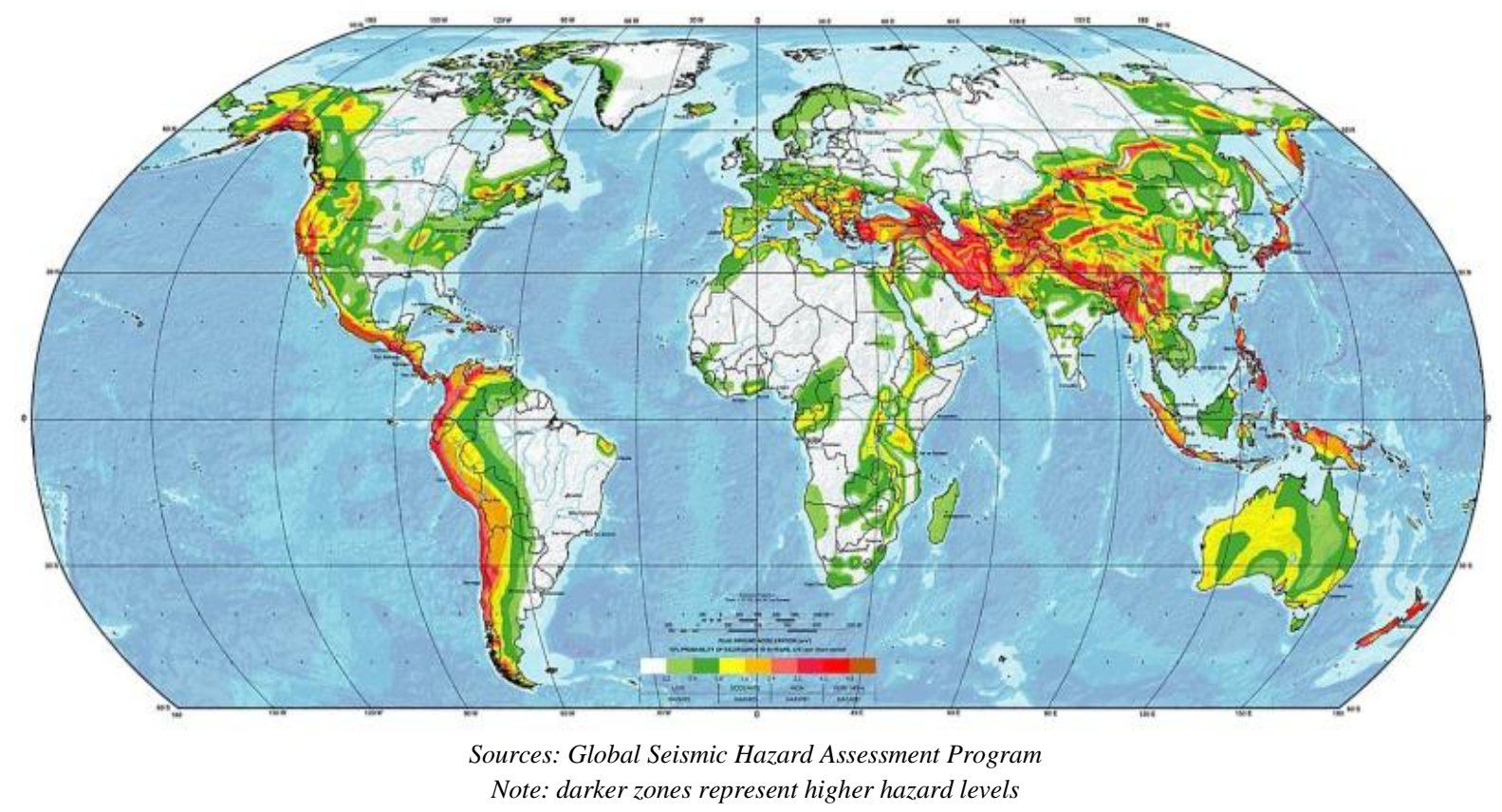

\footnotetext{
${ }^{23}$ It was estimated that about two-thirds of those affected by natural disasters in Mexico are poor or extremely poor, as they often live in hazard-prone urban areas and in low-quality houses, often as squatters, or in rural areas prone to flooding and other perils (Secretaría de Desarrollo Social, 2001).
} 


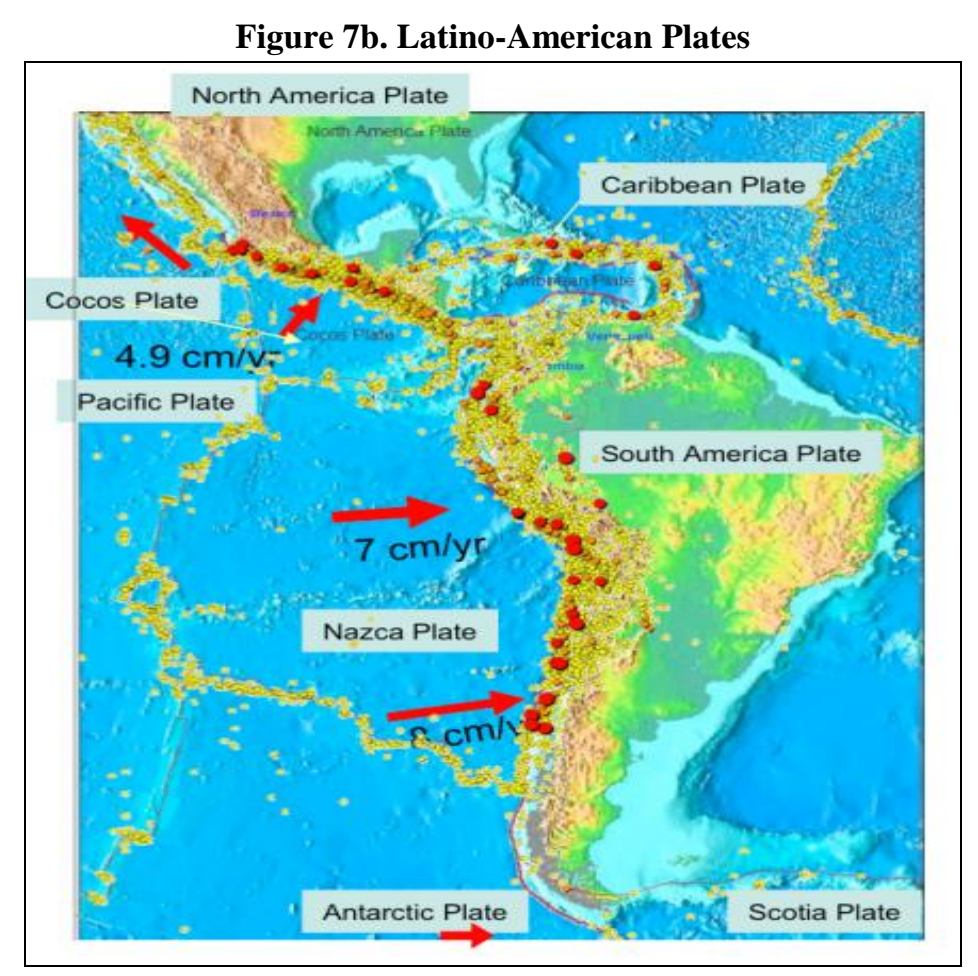

Sources: AIR Worldwide

Figure 7c. World Map of Tropical Storms Paths

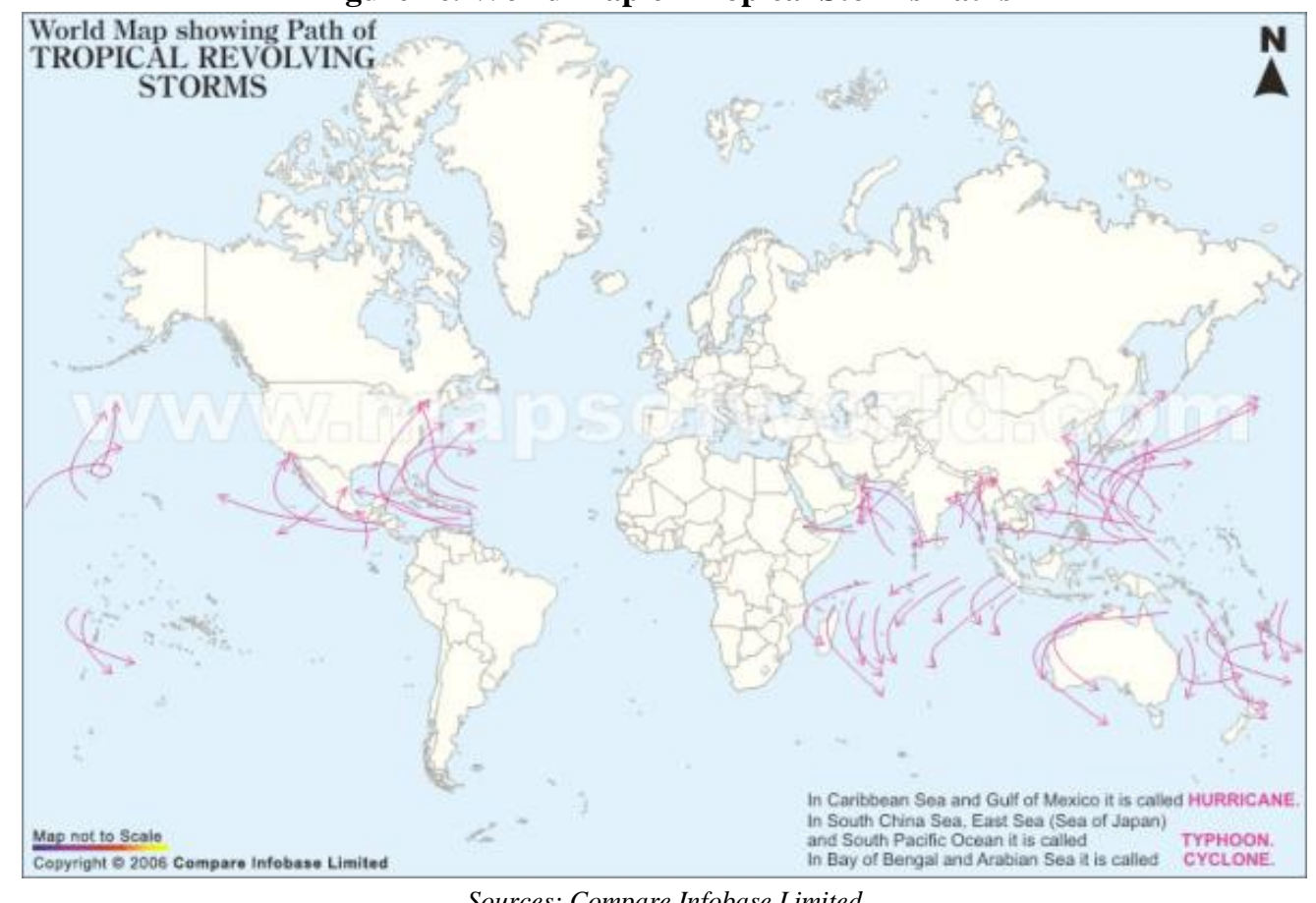

Sources: Compare Infobase Limited 
Figure 7d. Historical Tropical Storms

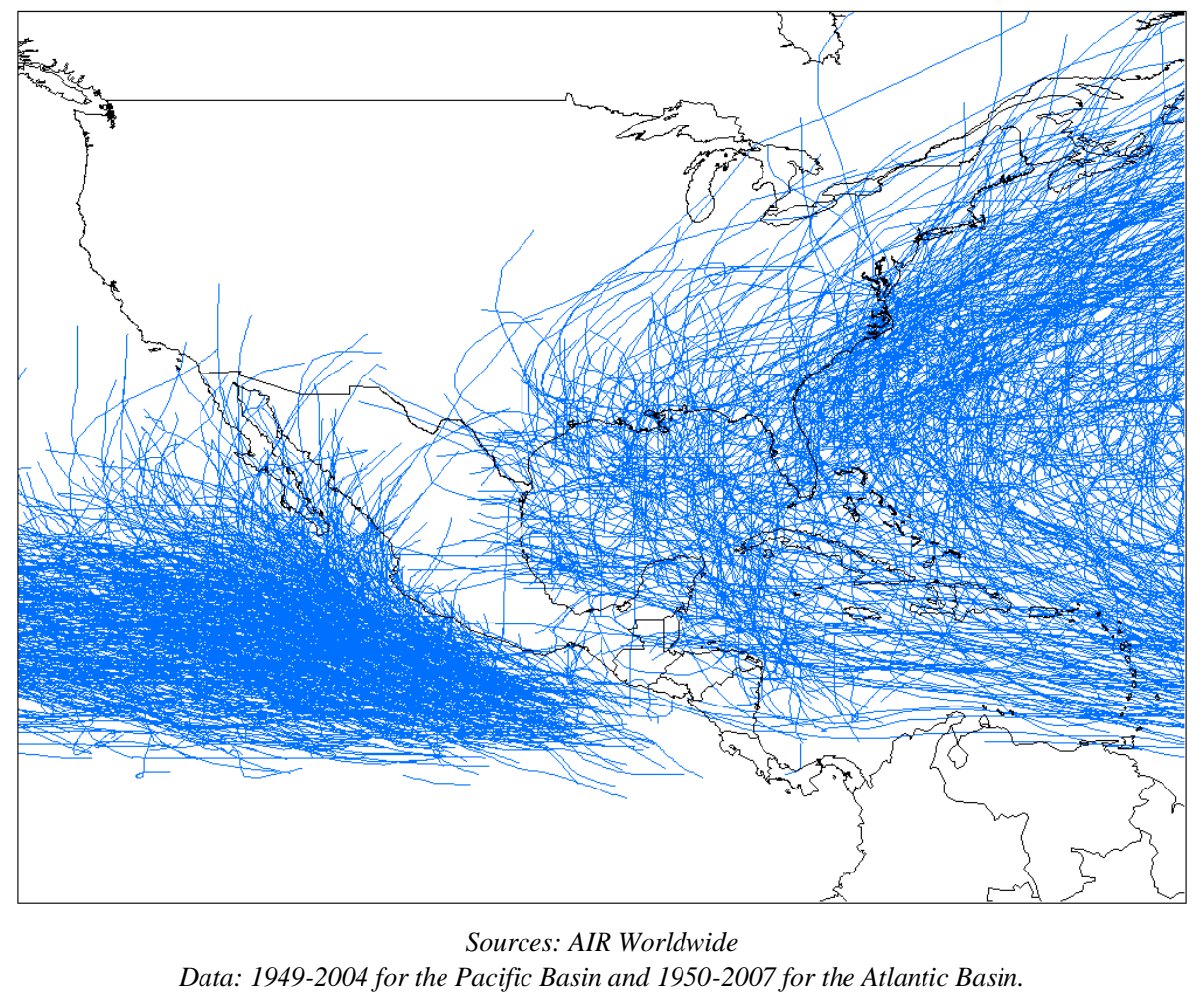

\section{Responsibilities of the Mexican Government for Disaster Financing}

Natural disasters for Mexico imply large fiscal liabilities for the government. To respond to this challenge, the Mexican federal government has been more active in developing a public policy strategy on risk management since the mid 1990s. The risk financing component of this strategy, government responsibilities - including provisions for impoverished people - are financed through the federal budget. In 1996, the Mexican government established a special allocation in the federal budget called the Fonden (in Spanish, El Fondo de Desastres Naturales; i.e., Natural Disaster Fund). This fund has two main purposes: 1) finance emergency expenses after a natural catastrophe to provide aid supplies to the affected population; 2) provide resources to the thirty-two Mexican states and to the federal agencies (that are in charge of federal infrastructure) for the recovery and reconstruction of the affected infrastructure and the dwellings of the low-income population in case of the occurrence of a severe natural catastrophe whose magnitude would overcome their budget's capacity.

The Fonden was established as an independent legal body. It transfers post-disaster financial resources to specific agencies, such as the Ministry of Transport for reconstruction of roads and bridges, the Ministry of Education for school reconstruction, the Ministry of Health for hospital reconstruction, and the Ministry of Social Development for low-income housing. The Fonden can also be used through a revolving fund by the Ministry of Finance in coordination with the Ministry of the Interior to provide funding for emergency response (e.g., medical 
supplies, food, shelter, food and temporary housing) over which the Ministry of the Interior has responsibility.

The associated national reserve fund, Fonden Trust, was created in 1999 along with thirty-two other state trusts (one for each Mexican state). If states or municipalities suffered a loss that surpassed their own capacity to handle the economic consequences of the disaster, the federal government would play the role of lender or insurer of last resort. The main advantage of this vehicle is its fiscal transparency (the resources are deposited in a trust and all the payments are made by the trustee directly to the contractors' accounts, so one knows how much is actually spent and by whom) and time efficiency in the distribution of aid supplies to victims of disasters.

Finally, the federal government also supports selected risk reduction projects across the country (e.g., improvements of public infrastructure). These different mechanisms are depicted in Figure 8 along with the timing of a catastrophe occurring.

Figure 8. Phases of Losses Financing in Mexico

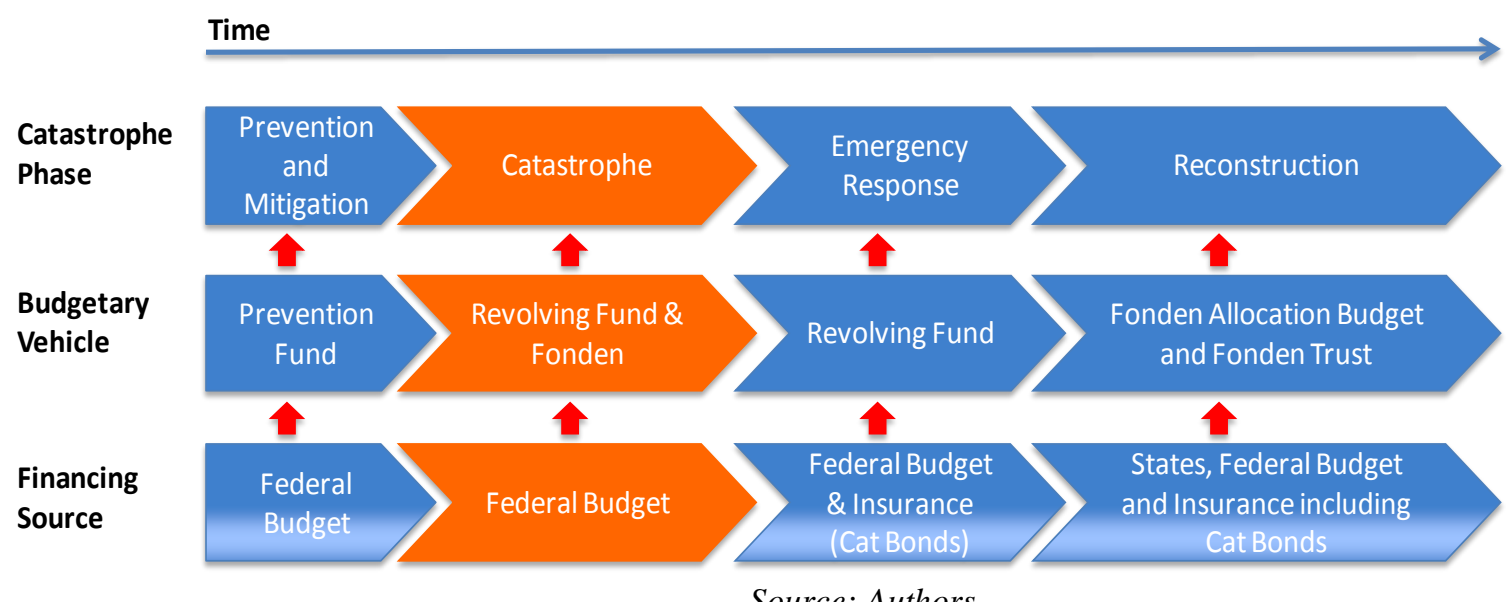

While the Fonden has remained the cornerstone of the Mexican strategy since 1996, several things have happened. The years 2001-2002 saw a low level of disaster loss, which gave the Mexican government the sense that continuing to support this dedicated line of budget was not a priority anymore and that the money could be better used elsewhere. As a result, the federal budget has significantly decreased its allocation to the Fonden since 2001 (apparent in Figure 9 below). But the following years saw more severe damages from natural disasters. The succeeding years' budgeted resources were below its spending, as was first the case in 2005 with budgeted resources close to $\$ 50$ million and spending near $\$ 800$ million after the severe hurricane season affected large parts of coastal Mexico.

The operation and accounting specificities of the Fonden is such that it will never run a deficit because the government is required by law to provide the necessary financial support from other sources (other lines of budget items and revenues from oil) to compensate states' losses if the Fonden Trust reserve is not enough to pay for the losses. This happened several times in the past few years, most recently in 2010. That year, the Fonden paid about $\$ 2$ billion as 
a result of an unusually devastating year of natural disasters, or about 6 times the average annual payment over the period 1999-2009.

Figure 9. Mexico's Fonden Budgeted and Spent Funds - 1999-2010 (in 2010 \$U.S.)

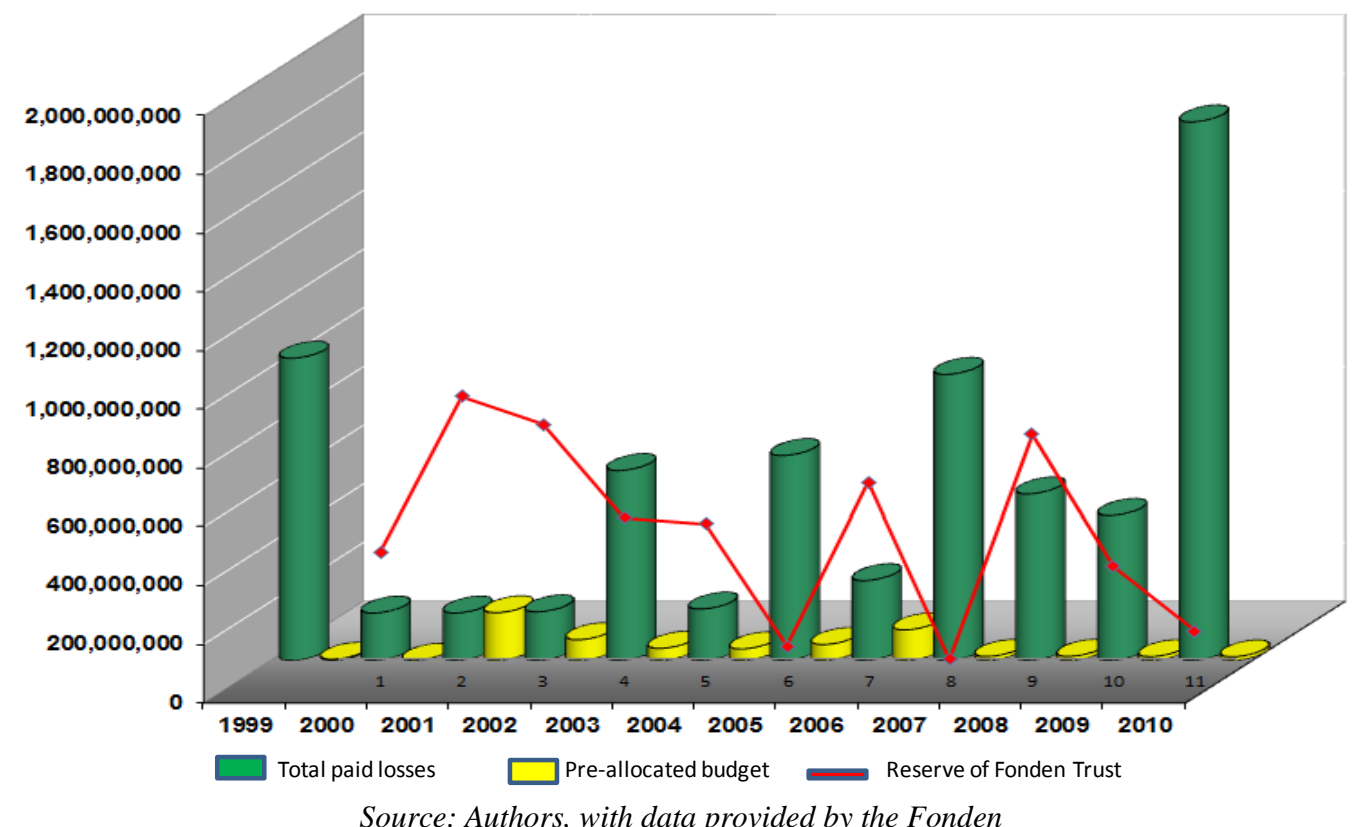

The series of disasters that occurred in the past decade in Mexico forced the government to look at alternative insurance strategies other than relying only on a federal government fund supported by taxpayers (which is potentially subject to raiding during mild years with minimal losses from natural catastrophes). Internal meetings took place within the Mexican government to ensure that government agencies at all levels would become more autonomous in developing their own insurance protection independent of the Fonden and also to analyze different risk financing alternatives to hedge against natural disaster shocks.

Fonden's rules of operation were also modified to allow the Fonden to buy insurance coverage from sources outside of the government, a change that is moving Mexico toward a risk hedging strategy. As a result, any financial risk transfer instruments to protect Fonden (thus, the Mexican government) would have to be implemented through a regular insurance policy. (Alternatively, governments can transfer risk through regular sovereign debt issuances). A new annual allocation to ensure the Fonden a minimum reserve to cover some of the damages caused by natural disasters and to purchase risk transfer instruments was voted into the new federal budget in 2006 (an allocation equivalent to about 0.4 percent of the national programmable budget). To access enough liquidity to support emergency response in the immediate aftermath of a disaster, Mexico decided to develop specific financial securities with quick disbursement that would be tailored to its specific needs. By doing so in 2006, Mexico transferred part of its public sector's exposure to earthquake risks to the international reinsurance and capital markets. In 2009, Mexico extended this protection to both earthquakes and hurricane risks. The next section details the different steps taken by the government of Mexico in that process. 


\section{B-2. PREPARATION AND EXECUTION OF THE 2009 MULTICAT PROGRAM:}

\section{A SEVEN-STEP PROCESS}

The MultiCat Mexico 2009 resulted from joint work between the World Bank's Department of Treasury (World Bank Treasury) and the Mexican Ministry of Finance (also called Hacienda) to create and develop a new type of financial transaction that would offer the government an easy-to-follow path towards more effective public catastrophe risk financing. To this end, the Mexican Ministry of Finance hired the World Bank Treasury to establish a catastrophe bond transaction to cover against hurricanes and earthquakes for three consecutive years and to establish an issuance program for such bonds. In this section we provide a step-bystep description of the creation of this bond, starting from discussions that took place in 2008 to the investor road show and the successful issuance of the bond in October 2009.

By doing so, we hope to provide the reader with a better understanding of the key steps, the important legal, economic and political elements to consider, as well as the timeline. We believe this can provide a good case study for other countries that wish to establish their own financial coverage solution against disasters. As we discussed in earlier sections of the report, while the Mexican Ministry of Finance chose to work on a catastrophe bond solution, other products might be more suitable for other countries. ${ }^{24}$

\section{Step 1: Understand the country's exposure and institutional framework and risk management infrastructure}

Different countries face different degrees of exposure to catastrophe risks. The first thing to consider in developing a national cat risk financing strategy is to appreciate what catastrophic risks the country is most exposed to. Secondly, since governments are complex bodies of regulations and legal structures, it is common in most countries to give the responsibility of managing the financial indemnification of victims of disasters (individuals, businesses or government entities) to a specific government body. Quite often, this is done within the Ministry of Finance or Ministry of the Interior.

In the case of Mexico, the Ministry of the Interior manages the Fonden through Banobras (a bank that belongs to the federal government) as trustee. The Ministry of Finance has provided the funding for this disaster fund since its inception. Major losses in 2005 led the Ministry of Finance to consider hedging against natural disaster shocks by transferring the financial risk off the balance sheet of Mexico. The decision to insure was analyzed and taken by the government while deciding, at the same time, on the best instrument for natural disaster insurance: either traditional reinsurance or a catastrophe bond. In this particular case, due to a desire to have a capital market traded instrument and for the collateralized component of a cat bond (guaranteed payment), Mexico elected a cat bond instead of reinsurance. The Ministry of Finance selected the

\footnotetext{
${ }^{24}$ The MultiCat program would provide funding for emergency expenses only. Interestingly, the Fonden is currently reaching out to the reinsurance industry to also purchase reinsurance of $\$ 600$ million in excess of $\$ 1$ billion to pay for reconstruction associated with future disasters.
} 
World Bank Treasury as arranger of a new multi-peril cat bond, with the Fonden as the cedant of earthquake and hurricane risk. The Bank would provide advice and hire the financial firms to execute the transaction.

\section{Step 2: Selection of the partners, roles and responsibilities}

Similar financial transactions in the private sector require several complementary areas of expertise: a modeling firm to quantify the exposure to disaster risks in a transparent manner; one or several legal firms to arrange all contracts in what is typically a multi-faceted regulatory system, ${ }^{25}$ and an investment bank to develop the financial product and sell it on the financial markets.

Experience and reputation of these firms are obviously very important. In the case of a government-bond issued in international markets, all of the above apply, but governments should also consider the participation of what could be called a global coordinator. The global coordinator should be a financial entity that regularly participates in the global capital markets and has experience in cat bonds so it can best represent the interests of the government. This is particularly relevant if the government does not have in-house financial expertise sufficient to negotiate the terms of the deal with sophisticated international players. For instance, one of the roles of the global coordinator is to propose a list of potential investment banks that are wellrecognized and have expertise in cat bonds, and to interact with the one that is selected during the issuance process.

As one of the main bond issuers in international capital markets, the World Bank Treasury was seen as a natural fit to play the role of global coordinator due to its strong relationships with both the Mexican government and major investment banks. The World Bank Treasury and the Ministry of Finance (Hacienda) shared the same appreciation of the ILS market in terms of sourcing insurance on efficient terms by spreading the risk among investors. With the continuing objective of expanding the range of investors in catastrophe bonds, the World Bank Treasury selected two market leaders, Goldman Sachs and Swiss Re Capital Markets. ${ }^{26}$ The third team member was Munich Re, which had been pursuing the development of their cat bond trading activity over the previous years. Note that while these firms represent the top of the class in arranging such ART instruments, there are firms in every major global financial center that can arrange such instruments for many countries in the world. The law firm Cadwalader, Wickersham \& Taft was selected as counsel for the transaction. The Mexican Ministry of Finance chose the law firm White \& Case to represent the Mexican Government. World Bank Treasury lawyers were to be involved in the drafting of the transaction as well. Mexico had an earthquake model developed for their 2006 CAT-Mex bond by AIR Worldwide, one of the leading catastrophe modeling firms. The firm was selected by the World Bank to update and

\footnotetext{
${ }^{25}$ The cat bond must follow public law and the insurance regulation of the issuer of the bond (Mexico) and it must have the legal documentation of an international bond - that is to say, the kind of bonds issued on the offshore market and not subject to a particular domestic regulation but rather to the legal framework established from the practice of the private sector over time.

${ }^{26}$ Swiss Re had also been co-leader for the 2006 CAT-Mex catastrophe bond and had a strong presence in Mexico.
} 
expand the model to hurricane risks as well (we will come back to this in more detail). The conclusion of this preparation phase was the drafting and signing of a service agreement between the Fonden and the World Bank. This agreement signed, the MultiCat Mexico 2009 could move on to execution.

\section{Step 3: Kick-off meeting and key decisions on the execution phase}

The execution phase was to be opened, according to cat bond market practice, with a kick-off meeting attended by all parties, which took place in Toronto, Canada. Fifteen representatives from all the stakeholders in the future deal gathered in Toronto in February, 2009 to frame, plan and decide upon the types of risks and the different geographical areas to be covered. The total budget and allocation among partners was discussed and the legal structure and the timeline for the project were determined. We briefly discuss these in turn.

\section{Hazards and geographical areas included in the cat bond}

Mexico was considering expanding the CAT-Mex (as discussed, the bond issued in 2006 and maturing in May 2009 and extended through a parametric insurance policy until October 2009) with a multi-peril cat bond. It was thus decided that, subject to approval by the board of the Fonden, the MultiCat bond would provide parametric coverage to the Fonden based on a "cat-in-the-box" trigger model to cover emergency expenses (earthquake's epicenter is within or on the boundary of the predefined zone on Pacific coast and the area surrounding Mexico City; location of storm track is within or on the boundary of the hurricane zones: Pacific hurricanes in two different parts of the coast; Atlantic hurricanes in the Yucatan Peninsula; see Figures 10a and $10 b)$.

It was also decided that one would use a binary definition for the triggers ${ }^{27}$ based on these parameters: earthquake magnitude and central pressure for hurricanes, and disaster declaration by the government of Mexico. This means that an earthquake or a hurricane occurring in an area not covered by one of these boxes or in one of these pre-defined boxes but below the pre-defined threshold would not trigger any payment to the Fonden.

\footnotetext{
27 That is, the insurance would pay the full amount if the magnitude of the earthquake (with epicenter in the box and hypocenter with depth above specified threshold values) or the central pressure of the storm while in the box went past a certain value; otherwise it would not pay anything. Alternative models use an algebraic function of various key parameters (magnitude, depth, distance from a city for an earthquake for instance) to compute the payout if the insurance is triggered. The calculation is explicit and can be replicated. The most recent techniques involve the use of an extensive and sophisticated model to estimate losses and compute payouts but the model remains a black-box, run by a third party. Investors tend to prefer binary triggers (a simpler and more transparent product). Some insurance buyers may prefer coverage based on an indemnity trigger, with the use of loss adjustment process. Given the risk financing of Mexico, which was focused on receiving a rapid notional post-disaster payment, this was not the priority for the Fonden.
} 
Figure 10a. Trigger Event Models for Earthquakes

\section{Earthquake Trigger Event Conditions}

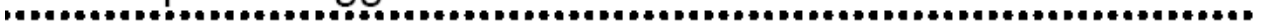

- $\quad 100 \%$ Principal Reduction of Class A Notes if Earthquake Trigger Event Conditions are met

- Payment of losses requires determination by the Calculation Agent (AIR at the commencement of the transaction) of Earthquake Trigger Event Conditions based on parameters as reported by the Earthquake Reporting Agency

- Earthquake Trigger Event Conditions:

- Earthquake Occurrence Time is during the Risk Period

- State of emergency declaration issued by the Secretaria de Gobernación ("SEGOB") and published in the Federal Official Gazette (the "SEGOB Declaration")

- Epicenter location in or on the boundary of an Earthquake Zone

- The Magnitude Condition and Depth Condition as set forth in the table below:

\begin{tabular}{|l|c|c|c|}
\hline & $\begin{array}{c}\text { Earthquake Zone A } \\
\text { (Northwest Cocos) }\end{array}$ & $\begin{array}{c}\text { Earthquake Zone B } \\
\text { (Central Cocos) }\end{array}$ & $\begin{array}{c}\text { Earthquake Zone C } \\
\text { (Mexico City) }\end{array}$ \\
\hline Magnitude $\left(\mathrm{M}_{\mathrm{w}}\right)$ & 7.9 or higher & 8.0 or higher & 7.4 or higher \\
\hline Depth $(\mathrm{km})$ & 200 or lower & 200 or lower & 200 or lower \\
\hline
\end{tabular}

See Offering Circular Supplement, pp. 5-6.

Figure 10b. Trigger Event Models for Hurricanes

\section{Hurricane Trigger Event Conditions}

\section{(1)}

- $100 \%$ Principal Reduction if Hurricane Trigger Event Conditions are met

- Payment of losses requires determination by the Calculation Agent (AIR at the commencement of the transaction) of Hurricane Trigger Event Conditions based on parameters as reported by the Hurricane Reporting Agency

- Hurricane Event Trigger Conditions:

- Hurricane Occurrence Date is during the Risk Period

- The SEGOB Declaration

- Location of Storm Track in or on boundary of the applicable Zone

- The lower of the central pressure as reported by the Hurricane Reporting Agency or interpolated by the Calculation Agent ("Calculated Central Pressure") as set forth in the table below:

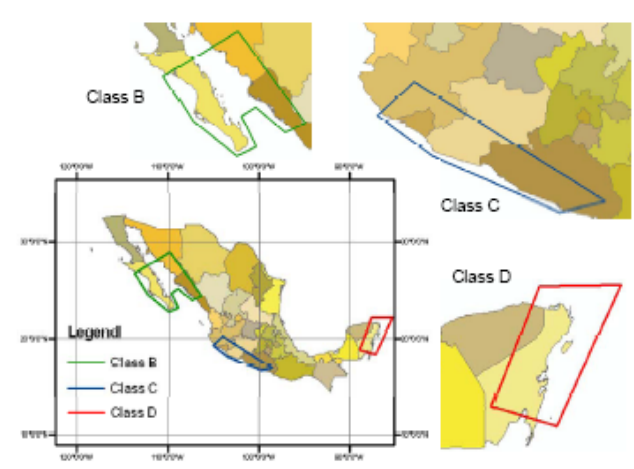

\begin{tabular}{|c|c|c|}
\hline $\begin{array}{c}\text { Class B } \\
\text { (Zone 1) }\end{array}$ & $\begin{array}{c}\text { Class C } \\
\text { (Zone 2) }\end{array}$ & $\begin{array}{c}\text { Class D } \\
\text { (Zone 3) }\end{array}$ \\
\hline $944 \mathrm{mb}$ or lower & $944 \mathrm{mb}$ or lower & $920 \mathrm{mb}$ or lower \\
\hline
\end{tabular}

See Offering Circular Supplement, pp. 6-8. 


\section{MultiCat Mexico structure}

The MultiCat Mexico structure (see Figure 11) would slightly differ from that of a traditional cat bond, in order to comply with Mexican public law requirements. The Fonden would be insured by a local insurance company. This insurance company would then be reinsured by Swiss Re, acting as a pure pass-through between the insurance company and the Special Purpose Vehicle (SPV).

Figure 11. Simplified MultiCat Mexico Structure

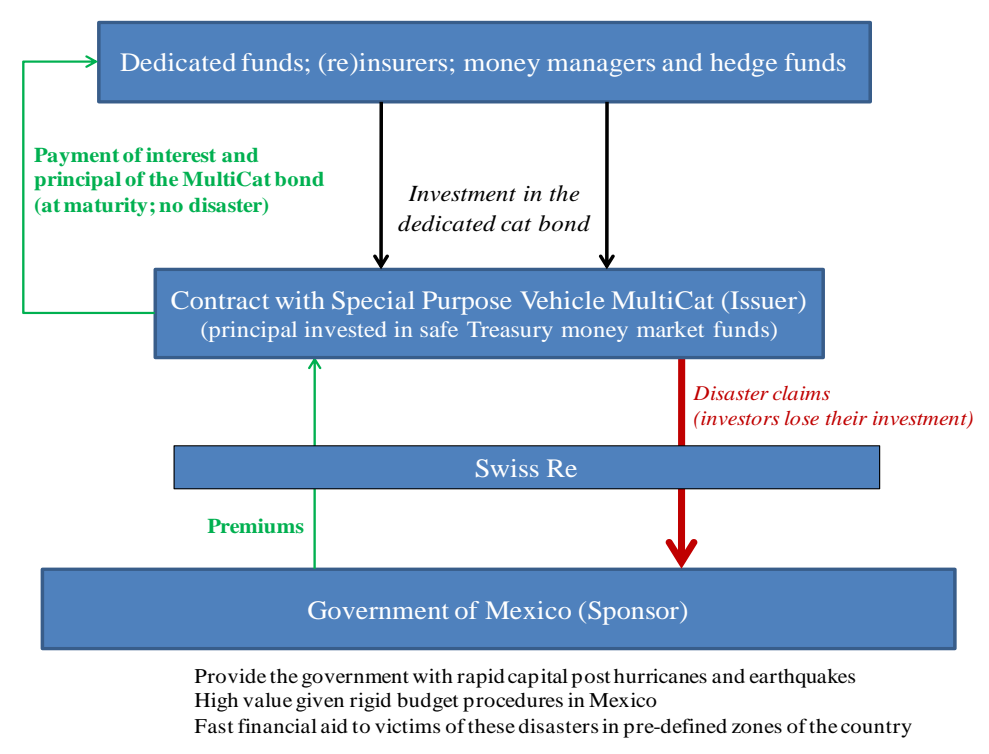

\section{Timeline and final terms}

The timeline for the transaction scheduled a launch date for the MultiCat of October 2009, eight months after the Toronto meeting. October was chosen because it corresponds to the end of the hurricane season, which would reduce the chance of the pricing be disrupted by the occurrence of severe summer hurricanes. Before launch, the main tasks included: establishing the final terms of the coverage (boxes, triggers) and drafting the legal documents for the transaction, including a prospectus of the MultiCat program plus pricing supplements of the bond; establishing the SPV, selecting an administrator, and obtaining a rating, elements to which we now turn.

\section{Step 4: Structuring the MultiCat bond}

With a fixed budget, the Ministry of Finance had to answer demands from other ministries, which were looking to enlarge the geographical region in which the epicenter of the earthquake or storm track would trigger the bond and to lower the attachment points of the triggers so the likelihood of being covered would be higher (as would the price). The team went through a relatively long optimization process from April to July 2009 to determine what part of the country would be covered and not covered, given the fixed budget allocated for this financial transaction by the Ministry of Finance. 
The size and shape of the covered areas, and the resulting trigger values yield a key parameter of any cat bond transaction: the Annual Expected Loss (AEL). AEL is typically expressed as a percentage of the insurance payout, to which a known multiple (determined by prevailing cat bond market conditions) is applied to compute the premium. The risk assessment phase, the choice of what is covered under the bond, and what is not covered, is obviously critical. The modeling firm provides estimates of potential losses that are exceeded with various annual probabilities (or losses corresponding to various mean return periods, which are the reciprocal of the annual probabilities). These results are the key drivers of the entire transaction, and for this reason, better field data quality will translate into better probability estimates.

\section{Type and amount of risk to transfer}

A fundamental decision is the definition of the type and amount of risk to transfer. Governments face several kinds of losses, for instance: business interruption (tax losses), reconstruction of public infrastructure, reconstruction of private infrastructure, and emergency response (shelter, food, debris removal and medical assistance). All of these types of losses could become significant and, depending on the level of economic development and financial system maturity, different countries could use different strategies. In any case, cat bonds seem a valuable instrument for quick disbursement to pay for emergency response, as was done in Mexico.

\section{Trigger mechanism}

The global coordinator can also play a vital role in deciding the trigger mechanism by guiding the government based on their needs; the global coordinator, assisted by the modeling firm and the investment bank, would structure this decision. Typically, a simple trigger mechanism is easier because it generates better pricing of the bond for the government and clarity for the investors (as discussed in Part A). At the same time, the government has to remain aware of the fraction of the actual losses covered by the payment made under a parametric insurance scheme. The risk assessment carried out by the risk modeling firm plays the main role in that regard. In the case of Mexico, AIR Worldwide generates all risk assessment studies based on the history of hurricanes and earthquakes in the country and advanced assessment methodologies. This hazard module is thus combined with a vulnerability assessment module (what damage would be caused by a given level of earthquake ground motion affecting buildings in a given city).

These calculations can be quite complex and require a good knowledge of the building structures in the exposed areas one wants to cover. Moreover, investors care significantly about the risk of manipulation, so reporting agencies on the triggering event would typically be selected outside of the sponsors' country. This was the case with MultiCat: it was the U.S. Geological Survey (USGS) for quakes and the U.S. National Hurricane Center for hurricanes. Also, the MultiCat is a double-trigger bond in that the physical trigger must be reached and Mexico must declare a state of emergency. 
Cat bond dealers establish a market line (premium versus AEL) around which all existing transactions are scattered and which gives a fairly good indication for these multiples. For instance, during the optimization process, AIR Worldwide runs their risk model for various scenarios of covered areas across Mexico and for different triggers to see whether the resulting premiums, given current market conditions at that time, would fit into the pre-defined budget. Another challenge was to bring hurricane and earthquake risks under the same bond. Goldman Sachs, Swiss Re and Munich Re confirmed that the investors would have interest in this pooled earthquake class of MultiCat notes. In the end, the earthquake note would pool together three regions (including Mexico City) for a shared \$140 million of coverage (class A tranches of the bond). Three distinct hurricane notes (class B, C and D) would each cover $\$ 50$ million (Table 1).

Standard \&Poor's, Moody's, and Fitch have all developed the capacity to rate cat bonds based on disaster risk parameters. Ratings are important in that they quantify the risk of default, thus setting a limit to the expansion of the population of investors (many investors will not invest in anything below certain investment grades). The rating agency plays the role of a third party verification agent, too: it verifies the consistency of the whole deal based on the disclosed documents on behalf of the investor. Rating agencies also signal the modification of the risk over the life of a bond. After review by Standard \& Poor's, class A, B and C notes were all rated "B"; the class D note was rated "BB-" (see Table 1).

Table 1. Mexico MultiCat Bond - Note Classes Description

\begin{tabular}{|c|c|c|c|c|}
\cline { 2 - 5 } \multicolumn{1}{c|}{} & Class A & Class B & Class C & Class D \\
\hline Hazards Covered & $\begin{array}{c}\text { Earthquakes in } \\
\text { three regions }\end{array}$ & $\begin{array}{c}\text { Hurricanes in } \\
\text { zone 1 }\end{array}$ & $\begin{array}{c}\text { Hurricanes in } \\
\text { zone 2 }\end{array}$ & $\begin{array}{c}\text { Hurricanes in } \\
\text { zone 3 }\end{array}$ \\
\hline Original Principal Amount & $\$ 140,000,000$ & $\$ 50,000,000$ & $\$ 50,000,000$ & $\$ 50,000,000$ \\
\hline Rating by S\&P & $\mathrm{B}$ & $\mathrm{B}$ & $\mathrm{B}$ & $\mathrm{BB}-$ \\
\hline $\begin{array}{c}\text { Interest Spread (over U.S. } \\
\text { Treasury money market funds) }\end{array}$ & $11.50 \%$ & $10.25 \%$ & $10.25 \%$ & $10.25 \%$ \\
\hline Maturity & 3 years & 3 years & 3 years & 3 years \\
\hline
\end{tabular}

The insurance premium is reflected in the interest spread. This premium is in turn transferred to bondholders as coupon payments (see Figure 11). The spread achieved on launch date (on the primary market) has to remain the private information of the Mexican Ministry of Finance, as is the case for every issuer in cat bond markets and in bond markets more generally. The secondary market spreads (equivalent to premium) established themselves at around 11.5 percent for class A notes (quake) and 10.25 percent for class B, C and D notes. Table 1 summarizes these data.

\section{Step 5: Establishment of the Special Purpose Vehicle (SPV) and drafting of the MultiCat legal documents}

Once the risk has been estimated for all the notes of the bond, the next step consists of transferring this quantified exposure to investors in the financial markets. This is typically done by the establishment of an offshore special purpose vehicle, or SPV (for tax purposes). In the 
case of Mexico, given the insurance regulations that applied to the Fonden as an insurance company, the risk had first to be reinsured (by Swiss Re in this case), which would then transfer that risk to a dedicated SPV, MultiCat Mexico 2009 Limited in the Cayman Islands. This process is called "transformation." The SPV is usually established under the guidance of the partner investment bank (by Goldman Sachs and Swiss Re in this case); given the high number of catastrophe bonds issued since 1996, this has become somewhat of a routine exercise.

The legal documents are relatively standard and very similar to the legal documentation used in Eurobond markets. The prospectus of the MultiCat program, however, reflects its "shelf" nature because the program was originally built by the World Bank Treasury to support a series of cat bonds for multiple governments. Based on the extensive legal documentation for the program, any future MultiCat bond will produce a relatively short supplemental document known as a "pricing supplement," assuming the current structure remains relatively unchanged. A pricing supplement contains all the technical information relative to the definition of the coverage: boxes, parameters and risk modeling. This information is detailed enough to provide the right level of transparency to investors. For instance, the information on the risk modeling in the MultiCat Mexico showed the trajectories of past hurricanes having gone through the predefined boxes and which could have triggered the bond (Hurricanes Dean, Gilbert, Allen and Ivan; see Figure 12). It also shows some past hurricanes which would have not triggered it (Hurricanes Charley, Carmen, Isidore, Wilma and the 1915 and 1971 hurricanes on the map). The storms crossing the box covering the Yucatan Peninsula are well-known to investors who specialize in cat bond portfolios.

Figure 12. Triggering Events.

Illustration with Trajectories of Some Pre-2009 Hurricanes through Zone 3

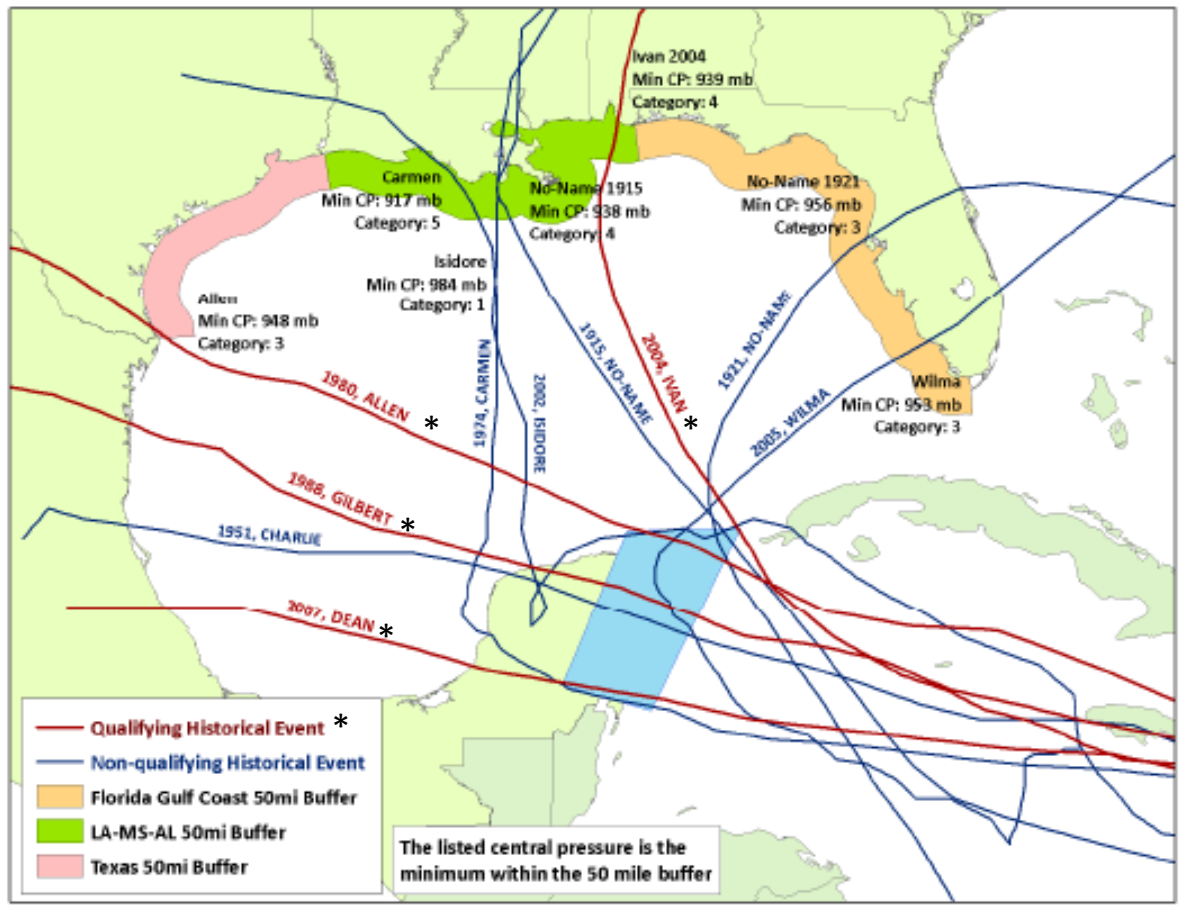

Sources: AIR Worldwide 


\section{Step 6: Launch road show, distribution and issuance}

When all of the above is done, the final step is to sell the bond to investors. Typically, the global coordinator (in this case, the World Bank Treasury) works with the partner investment bank to propose a strategy for placing the bond which would take into account market appetite, market trends, implementation costs, and a timeline. The timeline should factor in some type of seasonality risk, such as how far in advance of the start or the end of the hurricane season would the issuance of the bond occur.

Investor targets are developed along with a clear understanding of their needs; an estimate of pricing scale for tranches of exposure is developed depending on the selected trigger (e.g., indemnity versus parametric, as discussed in section A-2). October 2009 was then decided as the launch date for the MultiCat Mexico 2009. Information about the bond was distributed to key financial centers worldwide during a three-week period, subject to rule 144A limitations (e.g., all potential investors needed to be licensed qualified institutional buyers). There were three series of road shows for potential investors. They all had a similar group format: two representatives from the two lead managers (Goldman Sachs and Swiss Re), one from AIR Worldwide, one from the Ministry of Finance and one from the World Bank Treasury. Technical presentations were made about the structure of the bond and pricing.

By the day of its issuance, the bond was actually two-and-a-half times oversubscribed. The book (described in Tables 2 below) includes five types of investors. This was a nice signal given that it all happened not long after the financial crisis. ${ }^{28}$

Table 2a. MultiCat Mexico 2009-I Notes - Investor Distribution by Investor Type

\begin{tabular}{|c|c|c|}
\hline Investor Type & Amount Invested & Share \\
\hline Specialist ILS Managers & $\$ 115.75$ million & $39.91 \%$ \\
\hline Reinsurers & $\$ 97.50$ million & $33.62 \%$ \\
\hline Bank & $\$ 25$ million & $8.62 \%$ \\
\hline Hedge Fund & $\$ 21$ million & $7.24 \%$ \\
\hline Money Managers & $\$ 14.75$ million & $5.10 \%$ \\
\hline Reinsurer CatFund & $\$ 10.25$ million & $3.53 \%$ \\
\hline Endowment/Pension Funds & $\$ 5.75$ million & $1.98 \%$ \\
\hline
\end{tabular}

\footnotetext{
${ }^{28}$ The Lehman Brothers default in September 2008 marked a critical turning point for the catastrophe ILS market as it was a swap counterparty on several ILS transactions, causing investors to suffer losses from a collateral credit event, a scenario not initially contemplated by specialized investors. According to Goldman Sachs, these losses correspond to approximately 55 percent of the total losses suffered by the market since the birth of this market (the market also lost \$243 million due to Hurricane Katrina in 2005). No new cat bond was issued for several months after the bankruptcy of Lehman Brothers. The market resumed its activities in March of 2009 and grew during 2009. The resilience of the market was another sign of the fact that it was answering a fundamental need and not a temporary appetite for financial yield. The MultiCat Mexico 2009 was an additional signal of strength and a very positive contribution to the recovery of this market.
} 
Table 2b. MultiCat Mexico 2009-I Notes - Investor Distribution by Region

\begin{tabular}{|c|c|c|}
\hline Region & Amount Invested & Share \\
\hline US & $\$ 137.75$ million & $47.50 \%$ \\
\hline Bermuda & $\$ 98.75$ million & $34.06 \%$ \\
\hline Europe & $\$ 46.50$ million & $16.03 \%$ \\
\hline Japan & $\$ 7.00$ million & $2.41 \%$ \\
\hline
\end{tabular}

\section{Step 7: Conclude legal formalities}

The final step in the issuance of the catastrophe bond was for the Mexico Finance Ministry and the World Bank Treasury, as global coordinator for the deal, to finalize the insurance and reinsurance policies as well as the risk transfer contract between the reinsurance company and the SPV. The leader of this procedure is the legal firm whose duty it is to propose contract wording according to international practice, while considering local regulatory restrictions. Once the insurance policy was issued and the risk placed in the market, the World Bank Treasury concluded the business relationship with all parties. The government transferred the insurance premium in regular installments from the government's legal vehicle to the SPV to pay out investors should no trigger events occur during the three-year maturity of the bond.

Every time there is a catastrophic event (as discussed, the earthquake reporting agency is the USGS and the hurricane reporting agency is the U.S. National Hurricane Center), the Event Calculation Agent (AIR Worldwide was appointed for this role) will calculate if any payment from the bond is triggered based on the severity parameter of the event versus the trigger parameters in the bond.

Should this happen, investors might lose all their investment in a particular class of the bond, which would be used to quickly pay Mexico's Fonden. AIR Worldwide would directly notify all parties, and the World Bank Treasury team would coordinate the disbursement. 


\section{A Look Back At 2010: Two Events that Did Not Trigger the Cat Bond}

Mexico faced several disasters in the year 2010. The Baja California earthquake occurred on April 4, 2010 (7.2 on the moment magnitude scale). Most of the damage occurred in the twin cities of Mexicali and Calexico on the Mexico-United States border. Four people were killed and 100 people were injured. But because the quake was far north and outside of the boxes covered by the cat bond, the bond did not trigger.

In July 2010, Hurricane Alex struck near Soto la Marina, Tamaulipas as a Category 2 hurricane on the Saffir-Simpson scale. Major damages were reported in the State of Nuevo Leon but this event was also outside the scope of the cat bond, because it did not pass through the specified boxes and also because, even though it had gone through the covered area, its intensity was below the threshold necessary to trigger the bond.

These two examples illustrate the importance of the choice of the area to be covered by a cat bond and the selection of the trigger. If the bond covers the entire country and/or the trigger is a low probability of occurrence, then of course the government is more likely to receive some payment. But such a bond would be very costly because investors could more often lose their money. This is a trade-off any government or organization needs to consider seriously; this is also why the selection of a specific cat bond has to be thought through as part of a national strategy for catastrophe risk management and financing, and tailored to national priorities. 


\section{PART C}

\section{LESSONS LEARNED FOR CHILE AND OTHER COUNTRIES}



Early in the discussion about establishing the MultiCat program was the idea that it would be useful to combine under the coverage of such a bond not only catastrophe risks of a different nature (e.g., hurricanes and earthquakes), but also exposures from different countries. Geographical diversification is indeed an important component of risk management, and consideration was given to how this might lower the cost of the bond, making it more attractive to investors. At that time, not only the government of Mexico, but also the government of Chile were interested in having discussions with experts about the feasibility of integrating a sovereign cat bond solution as part of a national strategy to reduce governmental exposure to disasters.

While Chile decided in 2008 not to pursue this path, the combination of a major 8.8 earthquake in the Maulé region in February 2010 and the election of a new administration have triggered renewed attention to developing long-term sustainable disaster risk financing solutions. Because the budgetary situation of the Government of Chile was good in 2010, payments for emergency relief and for the reconstruction effort were made without major problems. But because disasters represent a contingent liability for the government and because economic conditions might not always be as favorable in the future, the possibility of establishing a dedicated disaster risk financing solution to protect public finance is important. As we discussed in section A-1, this can also been seen as a natural evolution of a country that has developed economically quite rapidly over the past few decades: Chile's GDP was \$31 billion in 1990 and $\$ 75$ billion in 2000. Over the period of 2000-2009 it more than doubled again to reach $\$ 164$ billion (in current dollars).

The purpose of this section is thus to shed some light on Chile's exposure to natural disasters and raise a few questions for its government to consider moving forward if the option of a sovereign cat bond is to be considered again. Our goal is not to provide an advanced probabilistic risk assessment, nor to study in great detail the current insurance market and government disaster liability. Rather, we build on the Mexican experience and focus on the importance of developing a properly designed cat bond solution that is aligned with political decisions of a broader national disaster management strategy.

\section{C-1. BRIEF HISTORY OF CHILEAN EARTHQUAKES}

Earthquakes and tsunamis are the more prominent natural hazards Chile faces. An historical look at natural disasters reveals that the country has been hit many times by earthquakes, including some of the most powerful ones recorded. Below, we describe several important ones among those. ${ }^{29}$ (See also Table 3).

\footnotetext{
${ }^{29}$ Other earthquakes include the following: 1730 (8.7 magnitude at central Valparaiso); 1835 (8.2 magnitude south-central Concepcion, 500 dead); 1877 (8.3 magnitude offshore northern Tarapaca, 34 dead); 1906 (8.2 magnitude at central Valparaiso, 3,882 dead); 1922 (8.5 magnitude on Chile-Argentina border); 1928 (7.6 magnitude at Talca, 225 dead); 1943 (8.2 magnitude near Illapel-Salamanca, 25 dead); 1965 (7.0 magnitude at Taltal, 1 dead); 1965 (7.4 magnitude at La Ligua, 400 dead); 1971 (7.5 magnitude in Valparaiso region, 90 dead); 1998 (7.1 magnitude near coast of northern Chile); 2002 (6.6 magnitude at ChileArgentina border region); 2003 (6.8 magnitude near central Chile); 2004 (6.6 magnitude near Bio-Bio, central Chile); 2005 (7.8 magnitude Tarapaca, northern Chile, 11 dead); 2007 (7.7 magnitude at Antofagasta, north Chile, 2 dead); 2007 (6.7 magnitude at Antofagasta); 2008 (6.3 magnitude at Tarapaca); 2009 (6.5 magnitude offshore Tarapaca). (Sources: U.S. Geological Survey).
} 
The 1868 Arica earthquake occurred on August 13 of that year, near the port of Arica (then part of Peru, now part of Chile). Its estimated magnitude was close to 9.0. A massive tsunami in the Pacific Ocean was produced by the earthquake, which was recorded in Hawaii, Japan and New Zealand. The earthquake caused major damages and the almost complete destruction of several cities, including Arica, Tacna, Moquegua, Mollendo, Ilo, Iquique, Torata and Arequipa. It has been estimated that the earthquake and resulting tsunami killed nearly 25,000 people.

The 1939 earthquake which hit south-central Chile on January 24 had an intensity of 8.3 on the Richter scale and caused the most deaths in Chile, around 28,000 (estimates from the United States Geological Survey).

The great 1960 Great Chilean earthquake was a massive earthquake that hit Chile on May 22. Its initial epicenter was near Cañete, some $900 \mathrm{~km}$ (435 miles) south of Santiago, with Temuco the closest large city, and Valdivia the most affected city. It was not the deadliest or most destructive quake on record, but is to date the most powerful earthquake ever recorded on Earth, rating 9.5 on the moment magnitude scale (note that the March 2011 Japanese earthquake was of magnitude 9.0). Its resulting tsunami affected southern Chile, Hawaii, Japan, the Philippines, eastern New Zealand, southeast Australia, and the Aleutian Islands in Alaska. Waves on the Chilean coasts were up to 25 meters $(82 \mathrm{ft})$. According to the Office of U.S. Foreign Disaster Assistance (OFDA)/Centre for Research on the Epidemiology of Disasters (CRED) International Disaster Database, 2 million people were affected and 3,000 died (see Table 3 below). Damages were estimated at about $\$ 800$ million.

Table 3. Ten Costliest Natural Disasters in Chile, 1950-2010 (nominal)

\begin{tabular}{|c|c|c|c|c|c|}
\hline Disaster & Date & $\begin{array}{c}\text { Nominal } \\
\text { Damage } \\
\text { (US\$ million) } \\
\end{array}$ & $\begin{array}{c}\text { Insured } \\
\text { Damage } \\
\text { (US\$ million) }\end{array}$ & $\begin{array}{c}\text { Number of } \\
\text { People } \\
\text { Affected } \\
\end{array}$ & $\begin{array}{c}\text { Total } \\
\text { Fatalities }\end{array}$ \\
\hline Maulé Earthquake & $27 / 02 / 2010$ & 30,000 & 8,000 & $2,671,556$ & 562 \\
\hline Santiago/Valparaiso Earthquake & $3 / 03 / 1985$ & 1,200 & 85 & $1,482,275$ & 180 \\
\hline Great Chilean Earthquake & $21 / 05 / 1960$ & 800 & $\mathrm{n} / \mathrm{a}$ & $2,003,000$ & 3,000 \\
\hline Earthquake & $6 / 05 / 1953$ & 500 & $\mathrm{n} / \mathrm{a}$ & 40 & 12 \\
\hline Wildfire & $2 / 01 / 1999$ & 280 & 80 & 1000 & 0 \\
\hline Earthquake & $8 / 07 / 1971$ & 236 & $\mathrm{n} / \mathrm{a}$ & $2,348,973$ & 85 \\
\hline Earthquake & March 1963 & 235 & $\mathrm{n} / \mathrm{a}$ & 460 & 280 \\
\hline Drought & Jan 1991 & 200 & $\mathrm{n} / \mathrm{a}$ & 0 & 0 \\
\hline Flood & $24 / 05 / 2002$ & 200 & 34.4 & 221,842 & 14 \\
\hline Flood (Santiago, Atacamo) & 10/06/1997 & 182 & $\mathrm{n} / \mathrm{a}$ & 76,800 & 22 \\
\hline
\end{tabular}

Source: The OFDA/CRED Database; www.em-dat.net - Université Catholique de Louvain (Belgium) and Aon (2011) 
The 1985 Santiago/Valparaiso earthquake occurred in March of that year. This 8.0 quake affected the central regions of Chile, killing 180 people, destroying 85,000 homes and damaging over 180,000 others. Thousands of aftershocks followed, including a magnitude 7.5 aftershock on April 9, 1985, located about $75 \mathrm{~km}$ southwest of Santiago (United States Geological Survey, 2010). Economic losses were said to be in the range of $\$ 1.2$ billion; as insurance had started to develop in Chile, this quake also triggered insurance losses of about $\$ 85$ million at that time (Axco Insurance Information Services, 2011).

\section{C-2. ECONOMIC AND INSURED IMPACTS OF THE 2010 MAULÉ EARTHQUAKE}

The massive 8.8 magnitude Maulé earthquake hit central Chile on February 27, 2010, causing widespread damage. The event, with an epicenter offshore 70 miles $(113 \mathrm{~km})$ from the country's third largest city, Concepcion (population of 373,000; 2002 census), and at a depth of 22 miles $(35 \mathrm{~km})$, triggered more than 100 aftershocks in the following days, including one of 6.9 magnitude, and a tsunami that devastated several coastal communities. For instance, wave heights of 2.6 meters were seen at Valparaiso (population of 268,000; 2002 census), 55 miles $(90 \mathrm{~km})$ west of Santiago. Over 2.6 million people were affected, 800,000 displaced; there were 562 fatalities and about 12,000 persons injured.

Material damage was extensive, especially in Concepcion, and in several coastal towns that were almost totally destroyed by the tsunami. This earthquake damaged five cities with over 100,000 inhabitants, 45 cities whose population exceeds 5,000, more than 900 villages and rural and coastal communities. More than 200,000 homes were destroyed or seriously damaged. Houses, bridges and roads collapsed or were severely damaged throughout the central region. The historic area of Santiago also sustained severe damage to old buildings. It is estimated that this catastrophe also destroyed or damaged 4,000 schools and 40 hospitals (17 of them were unusable).

This was one of the five largest earthquakes on record that impacted an area inhabited by more than 12.8 million people, or 75 percent of the population in Chile. The fact that the country had suffered many earthquakes and had a widespread application and enforcement of modern, seismic-resistant building codes certainly saved many people and the affected area's infrastructure from a much greater degree of devastation. Still, the earthquake generated devastating losses currently estimated at about US\$30 billion, which corresponds to 18 percent of the GDP of Chile (Ministerio Secretaría General de la Presidencia, 2011).

From the private insurance markets' perspective, this earthquake was a major event for Latin America. Estimates by the Chilean Insurance Association are that about $\$ 8$ billion of the losses (2010 prices) will be paid by insurers and reinsurers, the rest being paid by the victims themselves and the government. This makes the Maule earthquake the costliest insured earthquake since the 1994 earthquake in Northridge, California which inflicted over $\$ 20$ billion in insured losses (2010 prices). This also means that about 27 percent of the total economic 
losses were covered by insurance. As an element of comparison, only 7 percent of the economic losses of the 1985 Chilean earthquake described above had been covered by insurance (Asociacion de Aseguradores de Chile, 2011). This illustrates the growing role that insurance and reinsurance play in the country. The year before the Maule disaster, three-quarters of the larger industrial and commercial operations in Chile had fire and earthquake insurance, and about one-third of small and medium sized companies bought earthquake coverage. Twenty-four percent of homeowners in the country had earthquake insurance to protect their home (Aon, 2011).

Notably, local insurers are typically heavily reinsured on the international markets. As a result, 95 percent of the insured losses were reinsured. This is a very significant proportion; as a reference point, this figure would probably be in the range of 40 percent to 50 percent for a similar event in the United States. According to the Chilean Superintendent of Securities and Insurance (SVS), only about 1 to 3 percent of insured losses were paid by local insurers.

As a result of this disaster, premium rates for earthquake coverage around the country have increased by an average of 14 percent since the event. Reinsurance rates for Chile have increased significantly too, with catastrophe rates up by as much as 80 percent. More recent reinsurance renewals show a lower but still significant 50 percent increase, as of January 2011, compared the January 2010 prices (Aon, 2011). In the meantime, the government remains financially exposed to potential disasters in the coming years for the portion of the losses that would not be covered by insurance and reinsurance markets.

\section{C-3. WHY THE SELECTION OF DISASTER FINANCING SOLUTIONS IS IMPORTANT}

As discussed earlier, the 2010 Maulé earthquake triggered a renewed interest within the government of Chile about considering different options to reduce its financial exposure to future catastrophe losses. The SVS also intends to carry out a study in 2011 to develop a model of earthquake risk in Chile and then assess the adequacy of reserve levels to better determine whether insurers would be able to meet claims in the event of another large earthquake.

Although some earthquake risk models for Chile already exist in the catastrophe risk modeling industry to measure expected insured losses, undertaking a broader probabilistic risk assessment that combines seismic hazard and vulnerability function of all the current construction and industrial base in place will be an important step forward. This will help give an alternative view of not only the insured exposure but of the entire national exposure. In particular, developing comprehensive catastrophe models to determine what potential future losses will have to be paid by the victims themselves (individuals and firms) and their insurers (for those who have coverage), versus the taxpayers, will be critical in providing information needed to establish a national strategy.

To illustrate this point, Figure 13 below reports estimates by the catastrophe modeling firm AIR Worldwide on the relative return periods of several past earthquakes. These estimates 
are based on losses to the entire insurance industry. Given our discussion above, a quick calculation indicates that if the insurance penetration remains the same as it was in 2010 , for $\$ 1$ billion of insured losses, an additional $\$ 2.7$ billion burden would be placed on the government and the victims. (This ratio would change if insurance penetration increases in the future). Modeled losses in Figure 13 are produced using the AIR Chile Earthquake model and the AIR insurance industry exposure database for Chile. The bars are the modeled losses produced by their stochastic catalog and the arrows mark the approximate exceedance probability of the losses caused by these historical events if they were to occur today. Losses are on a ground-up basis (before the application of insurance terms such as deductibles) and are losses to the insurance industry's exposure. For example, there is slightly lower than a 2 percent annual probability that an event like the 1985 Santiago earthquake (in terms of equaling or exceeding its loss) will occur again in a given year, and slightly less than a 0.4 percent annual probability that an event comparable to the 1730 earthquake will occur in a given year.. ${ }^{30}$

Figure 13. Estimated Annual Exceedance Probabilities of Select Historical Earthquakes in Chile

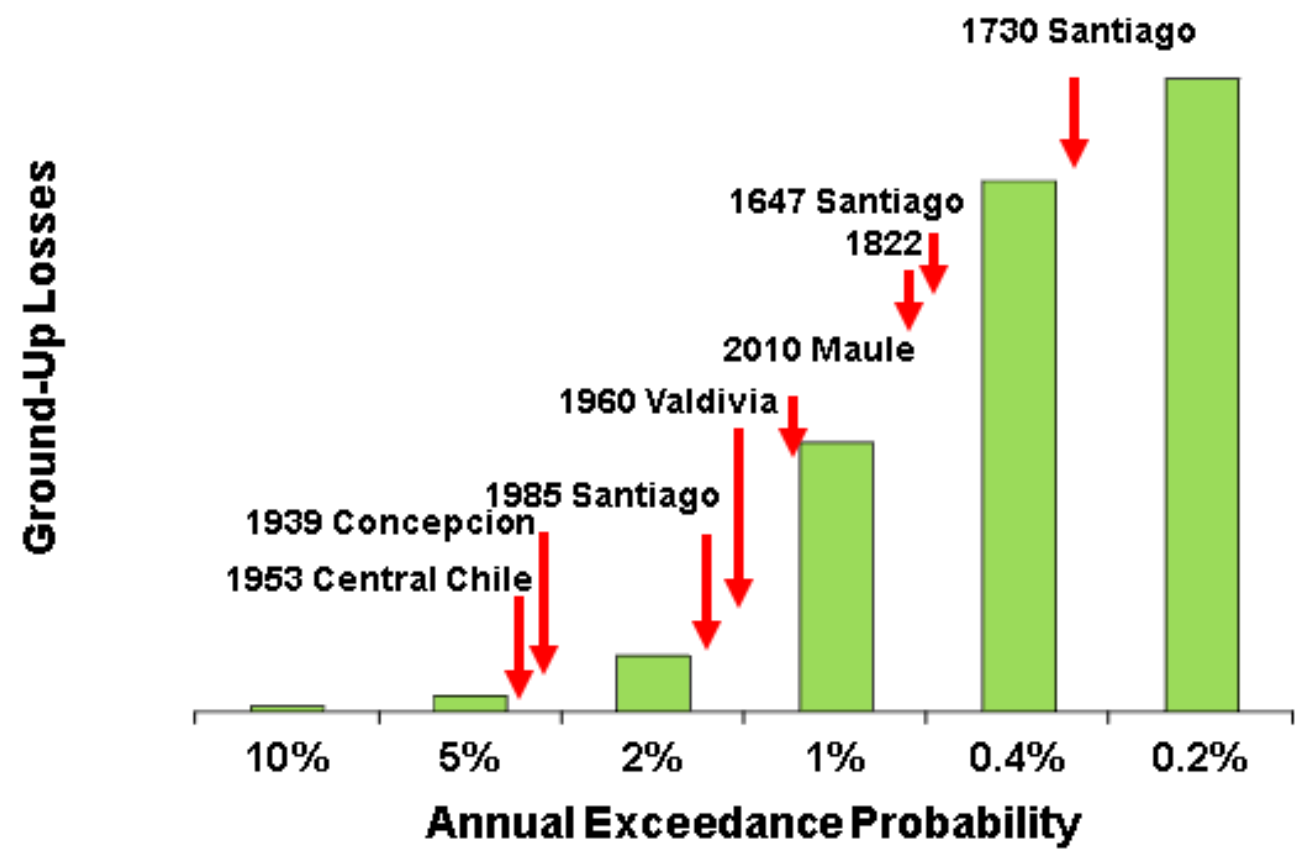

Sources: AIR Worldwide

Notably, the current catastrophe models in Chile have been developed mainly to help the insurance and reinsurance industry better measure its exposure. These models do not consider fatalities, homelessness, nor losses to public infrastructure.

Should the government also decide to transfer part of its exposure, it would first have to establish a comprehensive list of all its assets around the country, their construction type and

\footnotetext{
${ }^{30}$ For an older event, there is more uncertainty about the "true" parameters and loss, as such the placement of older events on the exceedance probability curve should be considered with some uncertainty.
} 
value, and then undertake a probabilistic risk assessment by crossing this information with hazard analysis. This could also be done on a smaller scale for areas or types of infrastructure considered strategic for the country. To our knowledge, this has not been done in Chile, yet.

One element that will be critical for the government to determine after such a catastrophe risk assessment is its risk appetite. What amount does the government want to transfer to a third party in exchange for a premium, and what amount will it retain as a potential budget liability? For the amount it wants to keep, it could rely on either its reserves or on its borrowing capacity post disaster. The government would be de facto self-insuring because, in either case, it bears the economic loss from future disasters (typically non-budgeted), and as a result would experience a reduction in net wealth. While borrowing can be a source of funds immediately after a disaster, funds might not always be easily accessible and in any event, borrowing does not reduce the economic loss.

For the portion of the potential disaster liability the government wants to transfer ex ante, what part could be covered by traditional reinsurance markets around the world versus via institutional investors interested in a sovereign cat bond to cover government exposure?

Once this question is answered, Part B of the report provides a detailed analysis of the "how to" by specifying each step of the process. Questions that will rise on the agenda of top policymakers include the following: Should the entire country be covered or only some of the major cities? Should the bond have an indemnity trigger or a parametric trigger? In the latter case, the selection of the expected return period for the events to be covered will be central. Is the goal to access quick liquidity in the aftermath of smaller disasters that might occur with some frequency (for example, 10 percent return period or once every 10 years), or for truly catastrophic ones only (for example, 0.4 percent, 0.2 percent or once every 250 or 500 years)? Government officials will also have to decide what budgetary lines they want to insure through a cat bond solution: emergency relief but not reconstruction cost (as was done in the Mexican MultiCat program), reconstruction cost only, or both.

The same questions would have to be considered for any country interested in developing more sophisticated disaster risk financing solutions. International experts can help, but answering those questions is fundamentally a policy decision that leaders in government have to make. 


\section{Conclusion}

This study was motivated by two concrete questions facing top government officials in view of the recent observed and growing impact of large-scale catastrophes, specifically: How can you better prepare your country economically to face future catastrophes and to ensure fast economic recovery post disaster? How can you immunize your fiscal policy against massive contingent shocks ex ante, and how can you reduce your dependence on international aid ex post?

In an attempt to answer these questions, this report offers an operational toolbox by:

A) Introducing a simplified framework for decision-makers to assess options available to them in designing their financial risk management policy, with a particular focus on catastrophe bond markets

B) Analyzing in full the fundamental and practical aspects of the MultiCat Mexico 2009 implemented in partnership by the government of Mexico and the World Bank

C) Extending the discussion to the case of earthquake in Chile

A government official willing to act on this basis is at once confronted with the need to have catastrophe risk insurance specialists in-house to undertake such a MultiCat bond issuance process. While the path to follow is known, a country's Ministry of Finance may not have the staff to deal and negotiate with seasoned capital market institutions, nor relate to more specialized actors such as law firms or risk modeling firms.

In the case of Mexico, the World Bank Treasury acted as arranger in a MultiCat transaction and also mentored a dedicated team in the Mexican government by working with them on the transaction. Through such a capacity building, the government stayed in control of the whole process, and subsequently used the MultiCat program on its own.

This type of knowledge transfer in an area of sovereign debt markets, where most governments may not have in-house expertise should be seen as a framework for action that has proven benefits. While this report has shown the "how to" of government's use of catastrophe bonds, we also highlighted some of the elements government leaders must keep in mind. "What are the costs of such instruments as compared to alternative financial coverage options?" "What risks does the government want to cover versus keep as potential liability to its budget?" We have illustrated some of these questions with the case of the Chilean government after the massive 8.8 earthquake that occurred there in February 2010 and cost a significant portion of the country's GDP.

As the cost of disasters has been significant in recent years and exposure to future catastrophes continues to increase, many more countries around the globe will soon have to develop properly designed catastrophe risk financial protection solutions (or redesign them). 
Finally, we should restate that financial coverage is only one element of a more comprehensive national strategy, which should combine risk assessment, risk perception, risk prevention, risk mitigation, and risk financing - and which also goes beyond natural disasters alone (to include, for example, terrorism, pandemics, and technological accidents).

In recent years, many more countries have expressed interest in developing such a comprehensive strategy that could be supported by a national risk management team reporting directly to the President, Prime Minister, or head of the Kingdom. ${ }^{31}$ Several of them are now doing it (Michel-Kerjan, 2011).

\footnotetext{
${ }^{31}$ Some countries, through their sovereign funds, could also start investing in dedicated investments to help foster quick economic recovery of their neighbors. If organized creatively across a given region, innovative financial solutions (such as postdisaster loans or catastrophe bonds) could provide a safety net to countries needing protection, while guaranteeing a high return on investment to dedicated investors. Ideally, richer countries would join as institutional investors (Michel-Kerjan, 2011).
} 


\section{References}

Anderson, R. R., F. Bendimerad, E. Canabarro, and M. Finkemeier (2000). "Analyzing Insurance-Linked Securities." Journal of Risk Finance, 1(2): 49-78.

Aon (2011). Chile: One Year On. February 2011.

Arrow, K. (1964). "The Role of Securities in the Optimal Allocation Risk Bearing." Review of Economic Studies, 31(2): 91-96.

Asociacion de Aseguradores de Chile (2011). "La Industria del Seguro en Chile y el terremoto del 27F." (presentation made on January 31, 2011).

Axco Insurance Information Services (2011). Insurance Market Report: Non-Life (PC) Chile.

Barrieu, P. and L. Albertini (2009). Handbook of Insurance Linked Securities. Chichester: Wiley and Sons.

Browne, M. J. and R. E. Hoyt (2000). "The Demand for Flood Insurance: Empirical Evidence." Journal of Risk and Uncertainty, 20(3): 291-306.

Cárdenas, V., S. Hochrainer, R. Mechler, G. Pflug, and J. Linnerooth-Bayer (2007). "Sovereign Financial Disaster Risk Management: The Case of Mexico.” Environmental Hazards, 7: 40-53.

Coval, J., J. Jurek, and E. Stafford (2009). "Economic Catastrophe Bonds". American Economic Review, 99(3): 628-666.

Cummins, D. and O. Mahul (2008). Catastrophe Risk Financing in Developing Countries. Washington, DC.: The World Bank.

Cummins, D. and M. Weiss (2009). "Convergence of Insurance and Financial Markets: Hybrid and Securitized Risk-Transfer Solutions." Journal of Risk and Insurance, 76(3): 493-545.

Debreu, G. (1959). The Theory of Value. New Haven, CT: Yale University Press.

Froot (ed.) (1999). The Financing of Catastrophe Risk. Chicago, IL.: Chicago University Press.

Froot, K. A., and P. O'Connell (2008). "On the Pricing of Intermediated Risks: Theory and Application to Catastrophe Reinsurance." Journal of Banking and Finance, 32: 69-85.

Ghesquiere, F. and O. Mahul (2010). "Financial Protection of the State against Natural Disasters." Policy Research Working Paper 5429, The World Bank, Washington, DC.

Grossi, P. and H. Kunreuther (eds.) (2005). Catastrophe Modeling: A New Approach to Managing Risk. New York, NY: Springer.

Gurenko, E. (2004). Catastrophe Risk and Reinsurance: A Country Risk Management Perspective, Risk Books, London.

Hardle, W. and B. Cabrera (2010). "Calibrating Cat Bonds for Mexican Earthquakes." Journal of Risk and Insurance, 77(3): 625-650.

Kunreuther, H. and E. Michel-Kerjan (2009). At War with the Weather. Cambridge, MA.: MIT Press.

Kunreuther, H. and R. Roth (1998). Paying the Price. Washington, DC.: Joseph Henry Press.

Lane, M. (ed.) (2002). Alternative Risk Strategies. London: Risk Waters Group.

Lane, M., and O. Mahul (2008). "Catastrophe Risk Pricing: An Empirical Analysis.” World Bank Policy Research Working Paper 4765.

Linnerooth-Bayer, J., R. Mechler and G. Pflug (2005). "Refocusing Disaster Aid.” Science, 309, 1044-1046.

Mechler, R. (2004). "Natural Disaster Risk Management and Financing Disaster Losses in Developing Countries." Verlag für Versicherungswirtschaft, Karlsruhe.

Michel-Kerjan, E. (2011). "Risk Management in MENA and Tunisia's 'Wake-up Call."” Knowledge@Wharton. The Wharton School, February 25. Available at: http://knowledge. wharton.upenn.edu/arabic/article.cfm?articleid=2605 
Michel-Kerjan, E. (2010a). "Hedging against Tomorrow's Catastrophes: How Sustainable Financial Solutions Can Help Protect against Extreme Events." in H. Kunreuther and M. Useem (eds.), Learning from Catastrophes, World Economic Forum Global Agenda Council on Natural Disasters. Philadelphia, PA: Wharton School Publishing.

Michel-Kerjan, E. (2010b). "Ensuring That Our Economies Remain Terror-Proof." The Huffington Post, June 23.

Michel-Kerjan, E. (2010c). "Pakistan's Challenge: How to Lead in the Wake of Catastrophe." The Washington Post, September 2.

Michel-Kerjan, E. (2010d). "Catastrophe Economics: The U.S. National Flood Insurance Program." Journal of Economic Perspectives. 24(4): 165-86.

Michel-Kerjan, E. and F. Morlaye (2008). "Extreme Events, Global Warming, and Insurance-Linked Securities: How to Trigger the 'Tipping Point'." Geneva Papers on Risk and Insurance, 33(1): 153-176.

Michel-Kerjan, E. and P. Slovic (eds.) (2010). The Irrational Economist. New York: PublicAffairs Press.

Ministerio Secretaría General de la Presidencia (2011). Balance de Reconstrucción. A un año del 27-F. División de Estudios, February 21, Chile.

Moss, D. (2002). When All Else Fails. Government as the Ultimate Risk Manager. Cambridge MA: Harvard University Press.

OECD (2010). Catastrophe-Linked Securities and Capital Markets. OECD High Level Advisory Board on Financial Management of Large-scale Catastrophes. Paris.

OECD (2008). Financial Management of Large-Scale Catastrophes. Policy Issues in Insurance $\mathrm{n}^{\circ} 12$. OECD High Level Advisory Board on Financial Management of Large-scale Catastrophes. Paris.

OECD (2005). Terrorism Insurance in OECD Countries. Financial Affairs Directorate. Paris.

Raschky, P. A. and M. Schwindt (2008). "Hazardous aid? The crowding-out effect of international charity" in Martorell, S., Guedes Soares, C. and Barnett, J. Safety, Reliability and Risk Analysis Theory, Methods and Applications. Taylor \& Francis Group, London.

Risk Management Solutions (RMS) (2011). Estimating Insured Losses from the 2011 Tohoku, Japan Earthquake and Tsunami. RMS Special Report. Available at: http://www.rms.com/Publications/2011TohokuReport_041111.pdf

Secretaría de Desarrollo Social (2001). Programa Nacional de Desarrollo Urbano y Ordenación del Territorio 2001-2006. Mexico.

Spry, J. (2009). "Non-life Insurance Securitization: Market Overview, Background and Evolution." in Handbook of Insurance Linked Securities, P. Barrieu and L. Albertini (eds.), Wiley and Sons: Chichester.

Swiss Re (2010a). "Natural Catastrophes and Man-Made Disasters in 2009: Catastrophes Claim Fewer Victims, Insured Losses Fall.” Sigma, No.1.

Swiss Re (2010b)." Insurance-linked securities market update." Newsletter: August. Available at: http://media.swissre.com/documents/ILSNewsletter_20100816_en.pdf

Thieken A. H., T. Petrow, H. Kreibich, B. Merz (2006). "Insurability and mitigation of flood losses in private households in Germany." Risk Analysis, 26(2), 383-395.

United States Geological Survey (2010). Historic Earthquakes: Offshore Valparaiso, Chile. March 29.

von Ungern-Sternberg, T. (2004). Efficient Monopolies. Oxford: Oxford University Press.

World Bank (2010). Natural Hazards, UnNatural Disasters. Washington, DC.

World Economic Forum (WEF) (2008). Convergence of Insurance and Capital Markets. Geneva. 


\section{Appendix 1. Cat Bond Series to Protect the U.S. California Earthquake Authority (CEA)}

As a result of the very costly 6.7-magnitude Northridge earthquake in January 1994, California homeowners' insurance generally excludes earthquake coverage today. Homeowners have the option of purchasing earthquake coverage through their homeowners' insurer if it provides such coverage or through the 1996-established CEA. In 2010, the CEA wrote about 70 percent of all residential earthquake policies in California (or about 800,000 policies in force).

Some of the risks of earthquake the CEA are exposed to have been transferred to the capital markets through multiple catastrophe bonds in recent years as part of CEA's broader reinsurance program. The Western Capital Ltd. catastrophe bond issued in February 2001 (see below) and many of the other issuances that came after follow the same general structure. In each case, CEA purchased reinsurance coverage from a reinsurer such as Lehman Re or Swiss Re. This reinsurer creates a special purpose vehicle and issues a bond; the proceeds are held in collateral and invested in assets. The bond's trigger is industry-loss indexed. Property Claims Services (PCS) collects survey data from insurers following an earthquake event and estimates industry losses. If industry losses exceed a certain threshold, then a proportion of the collateral is recovered by the reinsurer to pay out claims - and investors lose a proportion of their investment.

After the CEA signed a $\$ 100$ million reinsurance contract with Swiss Re, on February 15, 2001, Swiss Re issued a catastrophe bond through Western Capital Ltd., a Bermuda special purpose vehicle. The bond matured on Jan. 7, 2003 and was not triggered during its 23-month lifetime. Swiss Re Capital Markets (SRCM) and Goldman Sachs structured, underwrote, and co-led the private offering of $\$ 97$ million of floating rate notes and $\$ 3$ million of preference shares. If an earthquake had occurred, the catastrophe bond would have replenished Swiss Re's capital. Other relevant parties in the structure of this bond were General Reinsurance Corporation (swap counterparty), Property Claims Service (acting as reporting agent), and EQECAT (the cat modeler performing risk assessment).

Structure of the bond: The $\$ 97$ million in proceeds from bond issuance were placed into a collateral account and invested in high-quality assets with up to a 15-year final maturity. The returns on these assets are swapped with General Reinsurance acting as swap counterparty for a guaranteed LIBOR minus $0.10 \%$. In order to cover the spread above LIBOR, Swiss Re makes periodic payments to Western Capital Ltd. under a contract at an annual rate of $5.20 \%$. Therefore, the total coupon paid to the bond-holding investors is LIBOR plus $5.10 \%$.

Index: The cat bond was indexed to industry loss. After a catastrophic earthquake occurs, Property Claims Services surveys insurers to estimate the industry loss due to the earthquake or fire following the earthquake. If industry losses had been in excess of $\$ 22.5$ billion, then the bond would have been triggered and a proportion of the collateral would have been returned to Swiss Re to pay off claims. If industry losses had reached $\$ 31.5$ billion, then investors would have lost both their coupon payments and principal (Grossi and Kunreuther, 2005).

After mixing industry-loss and parametric triggers (Redwood Capital X Ltd in 2007), Swiss Re issued a new one-year maturity $\$ 150$ million cat bond to protect its reinsurance program of the CEA (Redwood Capital XI Ltd) in December 2009. This new issuance is industry-loss indexed using estimates provided by Property Claims Services, returning to Swiss Re's original format of the bond. 


\section{Appendix 2. Cat Bond to Protect the Taiwanese Residential Earthquake Insurance Pool (TREIP)}

The Chi-Chi 7.3 earthquake in 1999 caused nearly \$10 billion in damage (less than \$1 billion of which was insured). As a result, the government of Taiwan created the Taiwanese Residential Earthquake Insurance Pool (TREIP) in an attempt to diversify earthquake risk through a combination of local coinsurance, a non-profit fund, reinsurance and government coverage. Historically, TREIP has used a combination of direct government aid and risk transfer mechanisms to provide for the continued solvency of Taiwanese insurers and reinsurers. Enrollment in TREIP is mandatory for all insurers and reinsurers that offer policies protecting against earthquake risk.

The government of Taiwan issued the first cat bond protecting against Taiwanese earthquake risk on August 25, 2003. The TREIP insurance scheme consists of a layer of traditional coinsurance, a layer of funds available through TREIP, a reinsurance layer including a cat bond, and a direct government aid layer available for severe losses: According to the risk analysis by the risk evaluation company, EQECAT, it was determined that the earthquake insurance scheme would originally have a cap of TWD $\$ 50$ billion (around $\$ 1.7$ billion or 400 -year return period).

While the cat bond represents only a small portion of the overall risk financing program, several reasons explained its issuance. First, the Taiwanese government hoped to gain a strategic negotiating position for reinsurance prices as well as more capacity than was available through traditional reinsurance. Second, it sought to provide a stable and diversified source of insurance capacity. Third, it sought to strengthen Taiwan's quality of credit in the global market. Fourth, it hoped to gain valuable experience and professional knowledge in the area of alternative risk transfer. ${ }^{32}$ These reasons, along with the guarantee of secure and rapid funding in the case of a catastrophe, prompted great support for TRIEP's issuance by Taiwanese insurance and reinsurance companies. The bond itself had a standardized form, borrowing key elements from the successful Japanese earthquake and typhoon bonds issued in years prior. It had a three-year maturity, an attachment point of TWD20 billion (\$700 million) with an indemnity trigger, and an estimated penetration probability of 0.81 percent. ${ }^{33}$ Like many other cat bonds with similar Sharpe ratios, TRIEP's Formosa Re bond (issued through the government-created Central Reinsurance Corporation) was oversubscribed by investors in the global market. According to Artemis data, the Taiwanese Finance Ministry reports that 53 percent of the investments were made by cat bond funds, 31 percent by hedge funds, 11 percent by money managers, and 5 percent by reinsurers seeking to diversify their portfolios. The bond expired on June 30, 2006 without being triggered.

Because of the government protection insurers and reinsurers have received against insolvency, earthquake risk coverage has risen from only one percent of the Taiwanese population in 1999 to nearly 25 percent in $2008 .{ }^{34}$ Following the increased take-up rate and accumulated risk, the limit of the scheme was increased to TWD $\$ 60$ billion as of 1st January, 2007 (around \$2 billion depending on currency rate). Of course in a country where one estimates that 75 percent of the population is exposed to earthquake risk, this is still low. In the aftermath of the March 2011 earthquake in Japan, discussions have taken place to transfer part of Taiwanese exposure to quake to the financial market on a much larger scale.

\footnotetext{
${ }^{32} \mathrm{http}: / / \mathrm{www} . c e n t r a l r e . c o m / e n c o n t e n t / e a r t h q u a k e / e a r t h q u a k e 01 . h t m$

${ }^{33} \mathrm{http} / / /$ www.ncu.edu.tw/ ncu7020/Files/Phd_Repord/95/Engineering/htm/papper.pdf

${ }^{34} \mathrm{http} / / / w w w . g c c a p i t a l i d e a s . c o m / 2008 / 12 / 28 /$ taiwan-catastrophe-reinsurance-market-2008/
} 
Appendix 3. Recent Catastrophe Bond Deals (January 2009-December 2010)

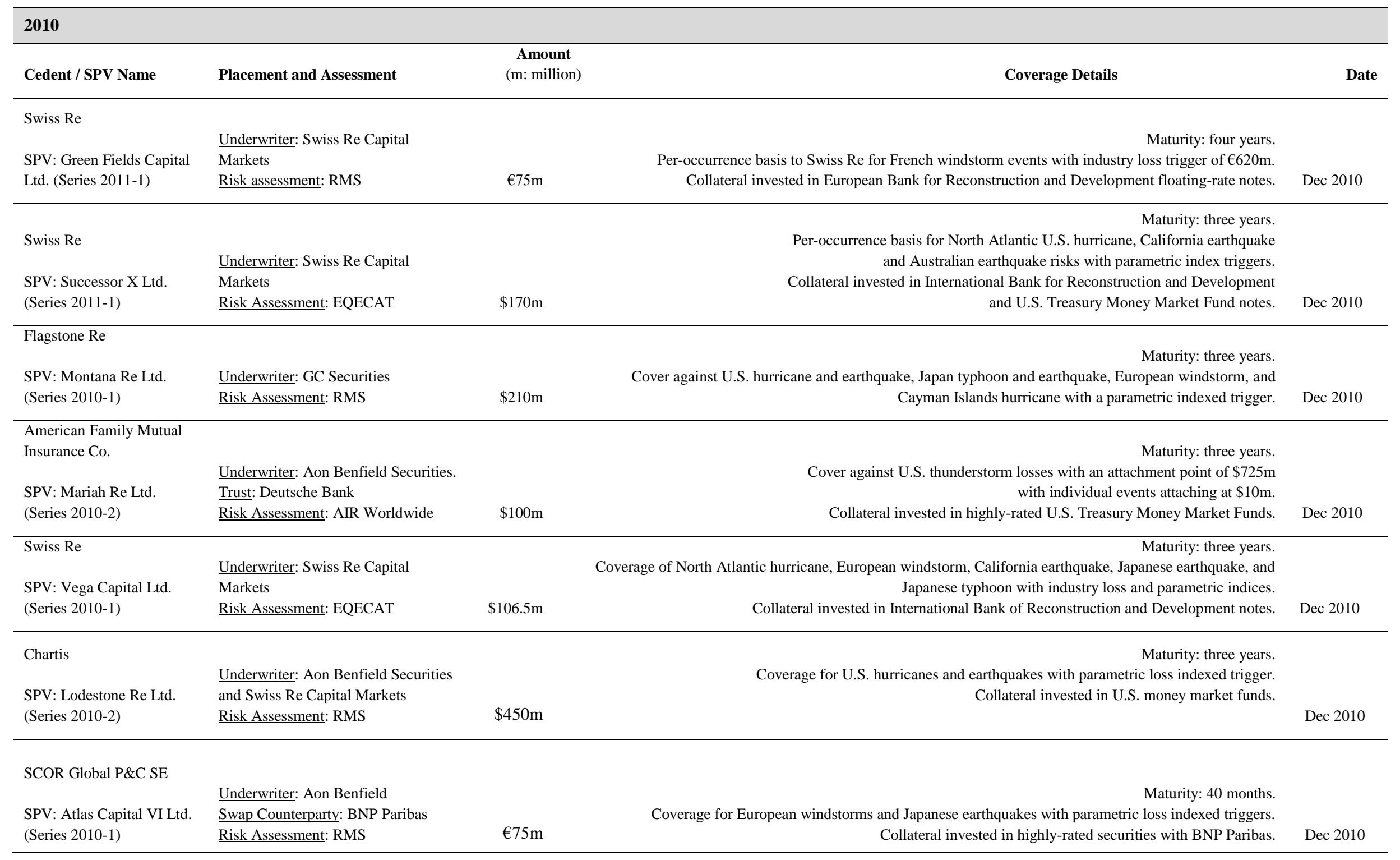




\begin{tabular}{|c|c|c|c|c|}
\hline USAA & \multirow{2}{*}{\multicolumn{2}{|c|}{ Underwriter: Goldman Sachs, Aon }} & & \\
\hline \multirow{3}{*}{$\begin{array}{l}\text { SPV: Residential } \\
\text { Reinsurance } 2010 \text { Ltd. } \\
\text { (Series 2010-II) }\end{array}$} & & & \\
\hline & Benfield Securities, Deutsche Bank & & & \\
\hline & $\underline{\text { Risk Assessment: AIR Worldwide }}$ & $\$ 300 \mathrm{~m}$ & $\begin{array}{l}\text { Coverage for U-S- hurricane, earthquake, thunderstorm, winter storm, and wildfire. } \\
\text { Collateral invested in U.S. treasury securities. }\end{array}$ & Dec 2010 \\
\hline American Family Mutual & \multicolumn{2}{|l|}{ Underwriter: Aon Benfield Securities. } & & \\
\hline Insurance Co. & & & Maturity: three years. & \\
\hline \multirow{4}{*}{$\begin{array}{l}\text { SPV: Mariah Re Ltd. } \\
\text { (Series 2010-1) }\end{array}$} & Trustee: Deutsche Bank & & Coverage against U.S. thunderstorm losses with an attachment point of $\$ 725 \mathrm{~m}$ & \\
\hline & Risk Assessment: AIR Worldwide & $\$ 100 \mathrm{~m}$ & $\begin{array}{r}\text { with individual events attaching at } \$ 10 \mathrm{~m} \text {. } \\
\text { Collateral invested in highly-rated U.S. Treasury Money Market Funds. }\end{array}$ & Nov 2010 \\
\hline & \multicolumn{2}{|l|}{ Underwriter: GC Securities and Swiss } & & \\
\hline & Re Capital Markets & & & \\
\hline AXA Global P\&C & $\underline{\text { Swap Counterparty: BNP Paribas }}$ & & \multirow{2}{*}{$\begin{array}{l}\text { Maturity: three years. } \\
\text { Per-occurrence basis coverage for European windstorms with industry-loss indexed trigger. } \\
\text { Collateral arranged in a tri-party repurchase agreement with BNP Paribas. }\end{array}$} & \\
\hline SPV: Calypso Capital Ltd. & Risk Assessment: RMS & $€ 275 \mathrm{~m}$ & & Oct 2010 \\
\hline & \multicolumn{2}{|l|}{ Underwriter: Swiss Re Capital } & & \\
\hline Groupama & Markets & & Maturity: 15 months. & \\
\hline SPV: Green Valley Ltd. & Risk Assessment: RMS & $€ 100 \mathrm{~m}$ & $\begin{array}{l}\text { Coverage for French windstorm risks with parametric indexed trigger. } \\
\text { Collateral invested in European Bank for Reconstruction and Development. }\end{array}$ & Sep 2010 \\
\hline \multicolumn{3}{|l|}{ Massachusetts Property } & & \\
\hline Insurance Underwriting & \multicolumn{2}{|l|}{ Underwriter: Guy Carpenter Securities } & & \\
\hline Association (MPIUA) & $\overline{\text { and Munich Re }}$ & & Maturity: three years. & \\
\hline SPV: Shore Re Ltd. & Risk Assessment: AIR Worldwide & $\$ 96 \mathrm{~m}$ & $\begin{array}{l}\text { Coverage for U.S. hurricane risks with indemnity trigger. } \\
\text { Collateral invested U.S. Treasury money market funds. }\end{array}$ & Jul 2010 \\
\hline \multicolumn{5}{|l|}{ State Farm } \\
\hline \multirow[t]{3}{*}{$\begin{array}{l}\text { SPV: Merna Reinsurance } \\
\text { III Ltd. }\end{array}$} & $\underline{\text { Underwriter: Aon Benfield Securities }}$ & $\$ 250 \mathrm{~m}$ & Coverage for U.S. hurricane, earthquake, thunderstorm, winter storm, and wildfire with indemnity trigger. & Jun 2010 \\
\hline & Underwriter: Goldman Sachs, Aon & & & \\
\hline & $\overline{\text { Benfield Securities, Deutsche Bank }}$ & & & \\
\hline \multirow[t]{2}{*}{ USAA } & & & & \\
\hline & Trustee: Bank of New York Mellon & & Maturity: three years & \\
\hline $\begin{array}{l}\text { SPV: Residential } \\
\text { Reinsurance } 2010 \text { Ltd. }\end{array}$ & $\underline{\text { Risk Assessment: AIR Worldwide }}$ & $\$ 405 \mathrm{~m}$ & $\begin{array}{r}\text { Per-occurrence coverage for U.S. hurricane, earthquake, thunderstorm, winter storm and wildfire. } \\
\text { Collateral invested in U.S. treasury bills. }\end{array}$ & Jun 2010 \\
\hline & Underwriter: Swiss Re Capital & & & \\
\hline Allianz & Markets, Aon Benfield Securities & & Maturity: three years. & \\
\hline SPV: Blue Fin Ltd. & Risk Assessment: AIR Worldwide & $\$ 150 \mathrm{~m}$ & $\begin{array}{l}\text { Coverage for U.S. hurricane and earthquake with parametric index triggers. } \\
\text { Collateral invested in U.S. Treasury securities. }\end{array}$ & May 2010 \\
\hline
\end{tabular}




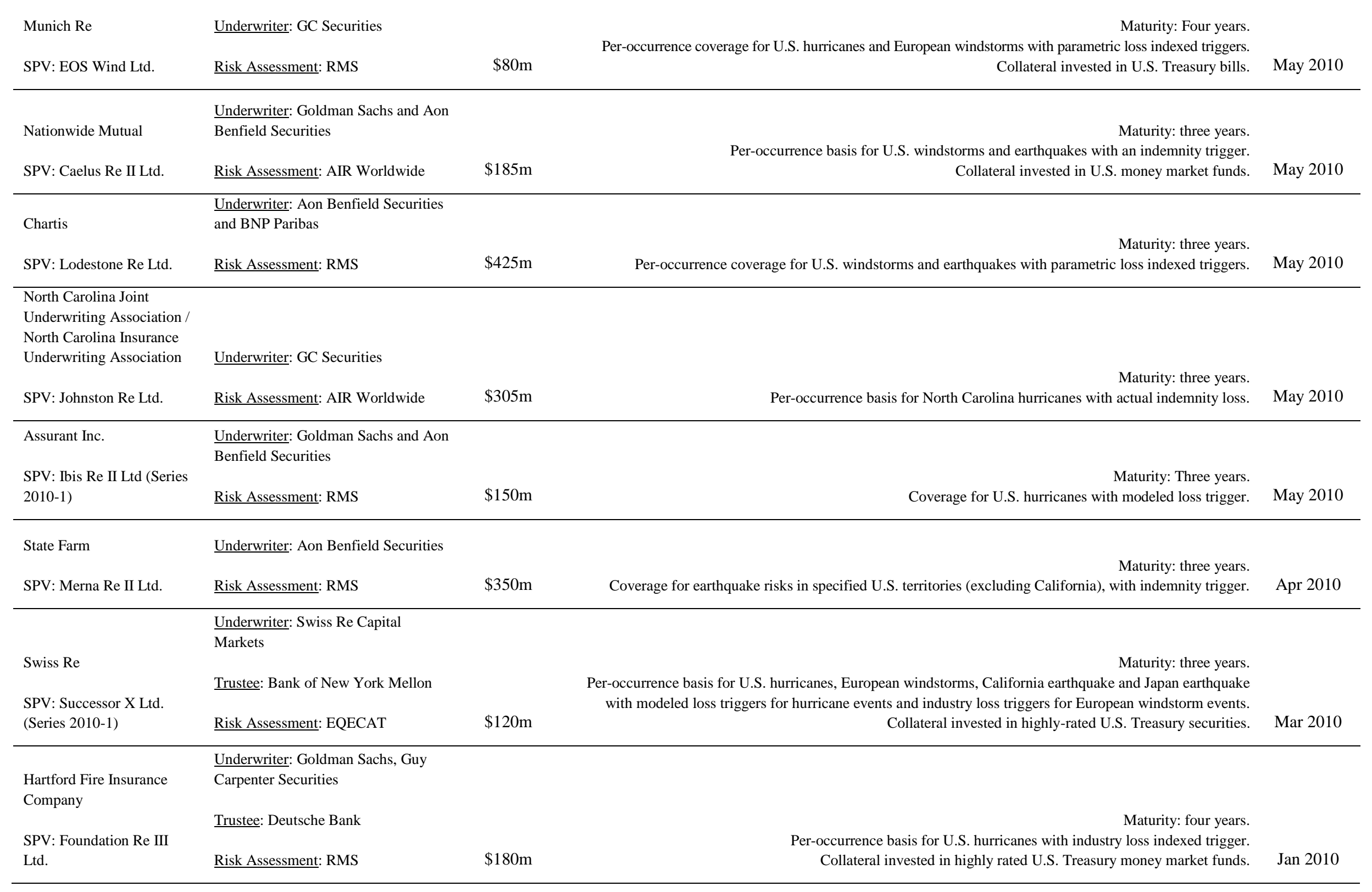




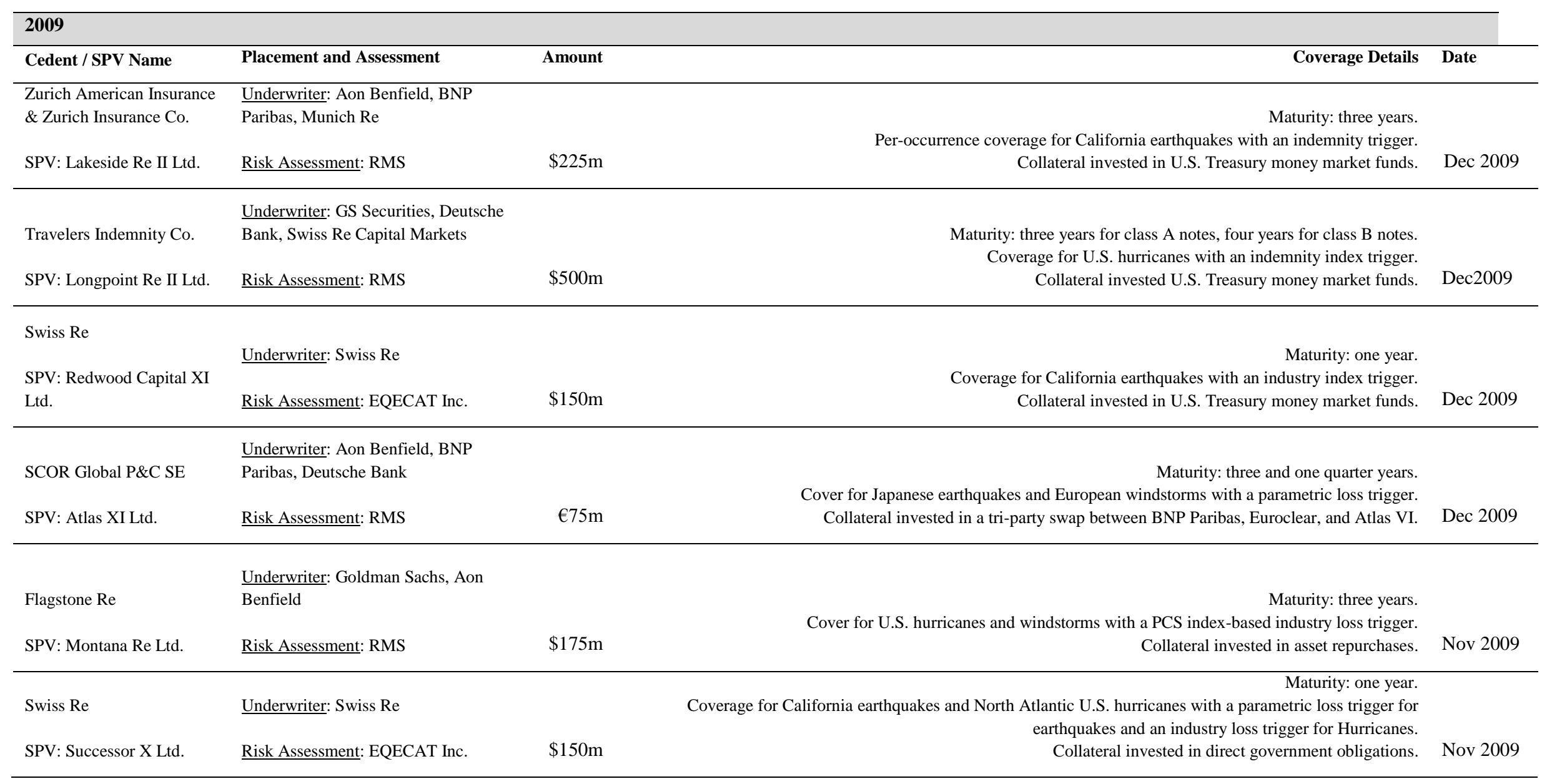




\begin{tabular}{|c|c|c|c|c|}
\hline $\begin{array}{l}\text { Agroasamex S.A. } \\
\text { SPV: MultiCat Mexico } \\
\text { 2009 Ltd. }\end{array}$ & $\begin{array}{l}\text { Underwriter: Swiss Re, Goldman } \\
\text { Sachs } \\
\text { Risk Assessment: AIR Worldwide Inc. }\end{array}$ & $\$ 290 m$ & $\begin{array}{r}\text { Maturity: three years. } \\
\text { Coverage for Mexico earthquakes and Atlantic and Pacific Mexican hurricanes } \\
\text { with a parametric loss trigger. }\end{array}$ & Oct 2009 \\
\hline $\begin{array}{l}\text { Hannover Re } \\
\text { SPV: Eurus II }\end{array}$ & $\begin{array}{l}\text { Underwriter: BNP Paribas, Aon } \\
\text { Benfield } \\
\text { Risk Assessment: AIR Worldwide Inc. }\end{array}$ & $€ 150 \mathrm{~m}$ & $\begin{array}{l}\text { Maturity: three and one half years. } \\
\text { Coverage for European windstorms with a parametric trigger. } \\
\text { Collateral invested in a tri party asset repurchase scheme. }\end{array}$ & Jul 2009 \\
\hline $\begin{array}{l}\text { Swiss Reinsurance } \\
\text { America Corporation } \\
\text { SPV: Parkton Ltd. }\end{array}$ & $\begin{array}{l}\text { Underwriter: Swiss Re, GC Securities } \\
\text { Risk Assessment: AIR Worldwide Inc. }\end{array}$ & $\$ 200 \mathrm{~m}$ & $\begin{array}{l}\text { Maturity: two years. } \\
\text { Coverage for North Carolina hurricanes with an indemnity trigger. }\end{array}$ & Jul 2009 \\
\hline $\begin{array}{l}\text { Swiss Reinsurance } \\
\text { America Corporation } \\
\text { SPV: Calabash Re III Ltd. }\end{array}$ & Underwriter: Swiss Re & $\$ 100 m$ & $\begin{array}{l}\text { Maturity: three years. } \\
\text { Coverage for U.S. hurricanes and earthquakes with an indemnity trigger. }\end{array}$ & Jun 2009 \\
\hline $\begin{array}{l}\text { Munich Re } \\
\text { SPV: Ianus Capital }\end{array}$ & Underwriter: JP Morgan & $€ 50 \mathrm{~m}$ & $\begin{array}{l}\text { Maturity: three years. } \\
\text { Coverage for U.S. windstorms with a parametric trigger. } \\
\text { Collateral invested in German floating-rate notes. }\end{array}$ & Jun 2009 \\
\hline $\begin{array}{l}\text { USAA } \\
\text { SPV: Residential Re } 2009 \\
\text { Ltd. }\end{array}$ & $\begin{array}{l}\text { Underwriter: Goldman Sachs, BNP } \\
\text { Paribas, Aon Benfield }\end{array}$ & $\$ 250 \mathrm{~m}$ & $\begin{array}{l}\text { Maturity: three years. } \\
\text { Cover for U.S. multiperil with an indemnity trigger. } \\
\text { Collateral invested in money market funds. }\end{array}$ & May 2009 \\
\hline $\begin{array}{l}\text { Swiss Re } \\
\text { SPV: Successor II Ltd. }\end{array}$ & Underwriter: Swiss Re & $\$ 60 \mathrm{~m}$ & $\begin{array}{r}\text { Maturity: one year. } \\
\text { Private placement coverage for U.S. hurricanes and California earthquakes with an indemnity trigger. }\end{array}$ & April 2009 \\
\hline $\begin{array}{l}\text { Assurant } \\
\text { SPV: Ibis Re Ltd. }\end{array}$ & $\begin{array}{l}\text { Underwriter: Goldman Sachs } \\
\text { Risk Assessment: RMS }\end{array}$ & $\$ 150 \mathrm{~m}$ & $\begin{array}{l}\text { Maturity: three years. } \\
\text { Coverage for U.S. hurricanes with a PCS index trigger. }\end{array}$ & April2009 \\
\hline $\begin{array}{l}\text { Allianz Argos } 14 \mathrm{GmbH} \\
\text { SPV: Blue Fin Ltd. }\end{array}$ & $\begin{array}{l}\text { Underwriter: Goldman Sachs, Aon } \\
\text { Benfield } \\
\underline{\text { Risk Assessment: AIR Worldwide }}\end{array}$ & $\$ 180 \mathrm{~m}$ & $\begin{array}{r}\text { Maturity: three years. } \\
\text { Coverage for U.S. hurricanes and earthquakes with an index trigger. } \\
\text { Collateral invested in KfW floating rate notes. }\end{array}$ & April 2009 \\
\hline SPV: Mystic Re II Ltd. & $\begin{array}{l}\text { Underwriter: Goldman Sachs, Swiss } \\
\operatorname{Re}\end{array}$ & $\$ 225 \mathrm{~m}$ & $\begin{array}{r}\text { Maturity: three years. } \\
\text { Coverage for U.S. hurricanes and earthquakes with an industry index trigger } \\
\text { Collateral invested in U.S. treasury securities. }\end{array}$ & Mar 2009 \\
\hline
\end{tabular}


Risk Assessment: AIR Worldwide

\begin{tabular}{|c|c|c|c|c|}
\hline \multicolumn{5}{|l|}{ Federal Insurance } \\
\hline \multicolumn{5}{|l|}{ Company / Chubb Group } \\
\hline Companies & Underwriter: FIC & & Maturity: three years. & \\
\hline SPV: East Lane Re III Ltd. & 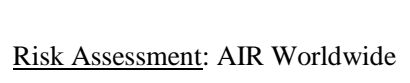 & $\$ 150 \mathrm{~m}$ & $\begin{array}{r}\text { Coverage for Florida hurricane with an indemnity trigger. } \\
\text { Collateral invested in U.S. treasury securities. }\end{array}$ & Feb 2009 \\
\hline \multirow[t]{2}{*}{ SCOR Global P\&C } & Underwriter: Deutsche Bank, BNP & & & \\
\hline & Paribas & & & \\
\hline \multirow{2}{*}{$\begin{array}{l}\text { SPV: Atlas Reinsurance V } \\
\text { Ltd. }\end{array}$} & & & Maturity: three years. & \\
\hline & Risk Assessment: AIR Worldwide & $\$ 200 \mathrm{~m}$ & Coverage for U.S. and Caribbean hurricanes with an industry loss trigger. & Feb 2009 \\
\hline
\end{tabular}

Sources: Market data and data from Artemis (www.Artemis.bm) 